Volume $5 \bullet$ Supplement $2 \bullet$ Pages S 1 -S 19

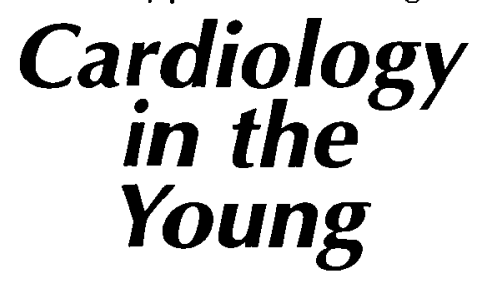

COPYRIGHTC 1995 BY WORLD PUBLISHERS LIMITED

ISSN 1047-9511

\title{
Abstracts of the 4th European Congress of Extracorporeal Life Support, Bergamo, 10-12 May 1995
}

01

Treatment of severe non-neonatal ARDS in children with surfactant and nitric oxide in a "pre-ECMO" situation Moller JC, Schaible TF, Reiss I, Artlich A, Gortner L Department of Pediatrios, Medical University of Lübeck, Lübeck, Germany

The use of exogenous surfactant and nitric oxide in neonates has reduced the number of infants requiring ECMO. The purpose of this study was to demonstrate whether these two therapeuticoptions might reduce thenumber of children over 28-days-old with severe ARDS requiring ECMO, without reducing chances of survival and morbidity. Over a 30 -month period, all nonneonatal ARDS patients transferred to our institution for ECMO evaluation were treated based on a study-algorithm - if they did not fulfill "fast entry criteria" ( $\mathrm{paO}_{2}<40$ for more than $3 \mathrm{hrs}$ ), we first tried different ventilation, vasodilatation, and hemodynamic strategies for a maximum of $4 \mathrm{hrs}$ (inv $\mathrm{I} /$ E ratio, HFOV, epoprostenol, high doses of norepinephrine, intratracheal $\mathrm{O}_{2}$ ) If the OI did not decrease by $>10,30-280 \mathrm{mg}$ natural surfactant or $1-20$ $\mathrm{ppm}$ nitric oxide were treatment options depending on the degree of pulmonary hypertension measured by echocardiography and by mixed venous sanuration measurements. It was possible to use $N O$ and surfactant sequentially. The patients had different etiologies of ARDS-near-drowning, pneumonia, immunosuppression, and sepsis. If the $\mathrm{OI}$ did not decrease by $>10$ in $8 \mathrm{hrs}$, ECMO was initiated. Fifteen patients were evaluated-5 improved with conventional therapy, their OI decreased without a relapse (mean Ol at beginning of the study: 38); 6 patients improved with surfactant therapy alone (mean OI: 54); 4 patients improved after surfactant and sequential NO treatment; 1 patient did not show any benefit from $\mathrm{NO}$ or surfactant and was put on ECMO;3 patients died (withdrawal oflife support because of severe brain damage caused by the underlying disease). We did not observe a death related to respiratory failure. No patient had to be discharged on oxygen. We conclude that a sophisticated treatment algorithm integrating different modern ARDS treatmentoptionscan reduce the number of patients requiring ECMO. Wespeculate, however, that theseoptionscan only be used effcctively in centers involved in ARDS treatment quite frequently and that these centers have to provide ECMO as one of their therapeutic tools.
02

A matched-pairs analysis of venoarterial and venovenous extracorporeal life support in neonatal respiratory failure Gauger PG, Hirschl RB, Delosh TN, Dechert RE, Tracy T, Bartlett RH University of Michigan Medical School, Ann Arbor, USA

Although it has previously been shown that venovenous (VV) extracorporeal life support (ECLS) confers a survival advantage over venoarterial (VA) ECLS, these results have been confounded by unknown differences in patient populations. To account for this, we performed a matchedpairs comparison of survival and complication rates in neonatal patients with respiratory failure managed with VA or double lumen VV access for ECLS. Retrospective matching of 643 VA and VV patient pairs from the Extracorporeal Life Support Organization Registry was performed. Pairs were matched by same year, same diagnosis, gestational age \pm 1 week, birch weight $\pm 0.3 \mathrm{~kg}$, and oxygenation index \pm 5 at initiation of ECLS. Statistical significance was defined for outcome and complication rates using McNemar's chi-square analysis. A survival advantage was identified in the VV group when compared to VA ( 91.5 vs $83.8 \%$; $\mathrm{p}<0.001)$. Hemolysis ( 19.3 vs $11.5 \%$; $p<0.001$ ) and cannula kinking (8.4 vs $1.4 \% ; \mathrm{p}<0.001$ ) were more frequent with VVECLS when compared with VA. The incidence of intracranial hemorrhage (ICH) was not significantly differentbetween the twogroups (10.6\% VA vs 9.3\% VV; $p=0.441)$. This is the first large matched-pairs analysis of $V$ and VA ECLS. From these data, we conclude: 1) survival is greater in VV when compared to VA ECLS; 2) significant mechanical complications such as cannula kinking and hemolysis are greater during VV ECLS than during VA ECLS; and 3) there is no identifiable difference in the incidence of $\mathrm{ICH}$ between the two groups. 
03

Prognosis and outcome of neonates treated either with venoarterial or venovenous ECMO

Varnholt V, Lasch P, Suske G, Hahn C, Kachel W Universitäts-Kinderklinik, Mannheim, Germany

The venovenous (VV) ECMO technique offers several advantages in comparison to venoarterial (VA) ECMO. For 3 years we have applied VVECMO in all neonates needing ECMO. Butsome infantsarestill treated with VA-ECMO, either due to a small jugular vein (not allowing the insertion of a 12 French double lumen catheter), or due to severe cardiocirculatory instability. In this study, we analyzed the prognosis and outcome of babies who underwent either VA-orVV-ECMO in the same period of time. From 1992 to 1994 ECMO therapy was done in 40 neonates after failure of maximal conventional management, NO-inhalation and HFOV. Twentyeight of 40 children were treated with VV-ECMO; in 3 of them, a switch to VA-ECMO was subsequently necessary. In 12 infants VA-ECMO was installed primarily (too small vessels, $n=6$; need for cardiac support, $n=6$ ). In the 2 groups ( 25 on $\mathrm{VV}$ - and 15 on VA-ECMO), there were no differences in the pre-ECMO course, in diagnosis, in $\mathrm{paO}_{2}, \mathrm{pCO}_{2}$ and $\mathrm{AaDO}_{2}$ before ECMO; the OI was higher in the VV-treated babies $(60 \pm 17$ vs $48 \pm 13$, $\mathrm{p}<0.03)$. This is perhaps due to the higher birth weight (3314 \pm 556 vs $2856 \pm 598 \mathrm{gm}, \mathrm{p}=0.05$ ) and the higher gestational age (39.8 \pm 1.7 vs $37.7 \pm 2.6$ wks, $\mathrm{p}<0.01$ ) in the VV-ECMO group, resulting in the administration of a higher MAP $\left(18.7 \pm 2.2\right.$ vs $\left.17.1 \pm 2.4 \mathrm{~cm} \mathrm{H}_{2} \mathrm{O}, \mathrm{p}<0.04\right)$; another explanation could be the cardiocirculatory instability of the babies later treated with VAECMO who did not tolerate a higher MAP. Severe ICHs occurred more frequently in the VA-treated babies ( 33 vs $8 \%, p<0.05$ ); the rate of other complications was equal in both groups. The mortality rate was $46 \%$ in the VA- and $16 \%$ in the VV-ECMO group $(\mathrm{p}<0.05)$. About one-third of neonatal ECMO patients will be treated with VA-ECMO, even if the VVECMO technique is available. The need for VA-ECMO implies, due to a higher number of preterm babies and/or a greater severity of illness before $\mathrm{ECMO}$, a higher rate of severe $\mathrm{ICH}$ and a higher mortality rate.

\section{4}

Extracorporeal membrane oxygenation as a perioperative support in pediatric cardiac surgery

Sosnowski AW, Khan JY, Moore H, Moore N, Hickey MStJ, Firmin RK Department of Cardiothoracic Surgery, Heart Link ECMO Centre, Glenfield Hospital, Leicester, UK

Extracorporeal membrane oxygenation (ECMO) is an established mode of therapy for refractory but recoverable respiratory failure. Recently, its use has been extended to provide postoperative cardiopulmonary support to cardiac patients unresponsive to maximal conventional intensive care. We report the retrospective analysis of our results in children treated with ECMO for either cardiopulmonary support related to cardiac surgery or preoperative stabilization. We reviewed the records of those patients who received ECMO for cardiac support between April 1991 and September 1994. Twenty-three children, aged 2 days to 10 years, were identified. Indications for ECMO were: low cardiac output syndrome (13), pulmonary hypertension (4), preoperative stabilization (2), failure to wean from cardiopulmonary bypass (2), postoperative cardiac arrest (1),ARDS and pancreatitis (1). Extrathoracic cannulation was used in the majority of patients $(n=20)$. The mode of ECMO was venoarterial in all but 2 patients. The median duration of cardiopulmonary support was 129 hours (range 18-647 hours). Cardiac recovery occurred in 15 children. Fourteen children survived discharge from hospital (survival rate 61\%). In conclusion, we have successfully used ECMO in the pre- and postoperative management of cardiac surgical patients with an overall survival of $65 \%$. Poor outcome was associated with 1) arrest prior to initiation of ECMO and 2) failure to wean from cardiopulmonary bypass after apparently adequate operative repair.
05

ECLS for acute respiratory distress syndrome related to syncitial virus infection

Renolleau S, Chevalier $J Y$

Hopital Armand-Trousseau, Paris, France

Respiratory syncitial virus bronchopulmonary infections are common in childhood. In a few cases infected infants develop an acure respiratory failure and need mechanical ventilation. Since 1987, nine infants who have developed an ARDS caused by RSV infection have been referred to our unit. They had persistant hypoxemia despite maximal conventional ventilation and met AREC criterias. Six patients were premature babies and required mechanical ventilation a few days because of a respiratory distress syndrome. Mean age at onser of ARDS was $4.36 \pm 3.65$ months. Mean duration of mechanical ventilation before AREC was 6.1 +2.9 days. Mean $\mathrm{AaDO}_{2}$ and oxygen index before AREC are shown in the table.

$$
\begin{array}{cccccc}
\mathrm{AaDO}_{2} \mathrm{H}-24 & \text { OI H-24 } & \mathrm{AaDO}_{2} \mathrm{H}-6 & \text { Ol H-6 } & \mathrm{AaDO}_{2} \mathrm{HO} & \text { Ol Ho } \\
5582 \pm 64 & 275 \pm 10.5 & 564 \pm 723 & 326 \pm 15.7 & 556.5 \pm 81.9 & 30.3 \pm 57
\end{array}
$$

Mean duration of ECLS was $195.9 \pm 92.2$ hours. Two infants had a persistant collapsus or hypoxemia. They were converted from AREC to venoarterial ECMO. Six patients survived (66.7\%). Mean duration of mechanical ventilation after decannulation for the survivors was $13.8 \pm 7$.1 days. Two of the parients who died had no disease before RSV infection. In conclusion, these data confirm that RSV infection can lead to ARDS even in healthy infants. ECLS can improve the outcome of these infants despite a poor respiratory condition.

06

Vascular reconstruction after ECMO

Gamba PG, Midrio P, Tommasoni N, Verlato F, Biban P, Zanon GF Department of Pediatric Surgery and the Pediatric-Angiology Service, University of Padua, Padua, Italy

Extracorporeal membrane oxygenation (ECMO) has become the treatment of choice for infants and newborns with cardiopulmonary failure unresponsive to conventional management. Since April 1993 in the Department of Pediatrics of Padua, we have treated 8 patients, 5 males and 3 females. Mean age was 22.6 months (12 hours- 96 months). Indications for treatment were in five cases acute respiratory failure, and one each with Bochdalek's hernia, multiple pulmonary arteriovenous fistulae and viral myocarditis. Mean treatment duration was $142 \mathrm{hrs}$ (66$243 \mathrm{hrs}$ ); four venoarterial and five venovenous bypass were performed, including one patient (diaphragmatic hernia) in whom the venovenous bypass was successively switched to venoarterial due to inadequate drainage. Six patients survived and two died. A double-lumen catheter (12 or $14 \mathrm{Fr}$ ) was used for venovenous bypass, while for venoarterial bypass, we performed the classic technique described by Bartlett and colleagues; the size of the catheter depended on the patient's weight. Our attention was especially placed on vascular reconstruction following ECMO procedure After analyzing different and controversial experiences, we chose to perform artery and vein reconstruction versus permanent ligature. In all the surviving cases, we anastomosed the vessels with interrupted $6-0$ or 8-0 monofilament suture utilizing $2.5 x$ magnifcation. Ten days and one month after the trial, an echo-color Doppler evaluated the results. All the reconstructed arteries showed patency; meanwhile $50 \%$ of the jugular veins were thrombosed. 
07

Extracorporeal membrane oxygenation with vevovenous bypass and apneic oxygenation for treatment of severe neonatal respiratory failure Bellan $C$, Somaschini $M$, Locatelli $G$, Glauber M, Colombo A Neonatal Intensive Care Unit and the Departments of Pediatric Surgery and Cardiac Surgery, Ospedali Riuniti, Bergamo, Italy

From July 1992 through December 1994, seven newborn infants with severe respiratory failure have been treated with VV ECMO and apneic oxygenation. Six newborns were referred from other hospitals; diagnoses were MAS (3), RDS (2), sepsis (1), CDH (1). Maximal ventilatory and pharmacological support were tried before ECMO; 3 infants received tolazoline, 3 surfactant, 3 high frequency ventilation, 1 PGE, 1 PGI, 2 nitric oxide. All the newborns were highly hypoxemic before cannulation: mean $\mathrm{AaDO}_{2}$ was $636 \pm 25$, OI $62 \pm 33, \mathrm{PaO}_{2} 28.1 \pm 18.6$ torr, $\mathrm{SaO}_{2} 52.8 \pm 35.5 \%$. Venovenous bypass was performed using a single lumen cannula, an alternating clamp, a nonocclusive roller pump and a silicon raceway tubing, allowing flow to be self-adjusted, depending on the volume and pressure in the circuit. Mean ACT was $165.8 \pm 33.3 \mathrm{sec}$. The average ECMO course was $162 \pm 126$ hours. Continuous hemodiafiltration was performed in one infant. Five of 7 neonates survived and 2 died (one with CDH because of pulmonary hypoplasia and a previous pulmonary hemorrhage, the other with sepsis because of cerebral death caused by hypoxic cardiac arrest before and during cannulation). Internal jugular vein was reconstructed in the 5 survivors. No significant technical complicationsoccurred. Follow-upat theage of 6 months and 1 year showed a normal growth and a normal neurological development in the 3 older infants tested. In conclusion, the extracorporeal lung support with VV bypass associated with apneic oxygenation is effective in treatment of severe neonatal respiratory failure unresponsive to maximal conventional and nonconventional ventilatory support. A good survival ratecan be achieved despite the critical condition of these patients. An early referral (transport prior to meeting ECMO criteria) and ECMO treatment is important to avoid the possible brain injuries and neurologic sequelae due to the hypoxic events preceding ECMO.

\section{8}

Severity and outcome of acute respiratory distress syndrome-the present place of ECLA - an analysis of 101 clinical studies

Steltzer H, Kraff P, Fradrich P, Koc D, Fitzgerald R, Hammerle AF Departments of Anesthesia and Intensive Care Medicine, University of Vienna, Vienna, Austria

Toevaluate ARDS severity and mortality over time, we performed an analysis of 254 full papers published on ARDS in adults between 1967 and 1994. Inclusion criteria were both outcome and $\mathrm{paO}_{2} / \mathrm{FiO}_{2}$ ratio ( $\mathrm{PF}$ ratio). Furthermore, number of patients, severity scores and mode of ventilatory support (including extracorporeal lung assist [ECLA]) were recorded in a data base. Statistical analysis was performed by calculating general linear models. Data are expressed as mean $\pm S D$ and a $p$ value $<0.05$ was considered significant; 101 original publications reported both mortality rateand $P F$ ratio and were included in the following analysis (3,264 parients). Average mortality was $53 \pm 22 \%$, with no trend to a reduction over time. Mortality was $53 \pm 22 \%$ before 1990 ( 49 papers), $52+22 \%$ in the years 1990 to 1993 (30 papers) and $51 \pm 19 \%$ in 1994 (22 papers). Mean PF ratio of the 3,264 included patients was $118 \pm 47 \mathrm{~mm} \mathrm{Hg}$ at a mean $\mathrm{FiO}_{2}$ of $73 \pm 17 \%$ and was unchanged over the years. Lung injury scores (LIS) were reported by 22

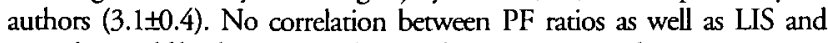
mortality could be demonstrated. Mortality in parients undergoing pressurelimited ventilation was significantly lower compared to patients ventilated volume-cycled ( $35 \pm 20$ vs $54+2 \%)$, despire lower $P F$ ratios $(98 \pm 31$ vs $131 \pm 59$ $\mathrm{mm} \mathrm{Hg}$ ). Within the study period, 10 authors investigated extracorporeal lung assist (ECLA) in 190 patients. Average mortality in these patients was $55 \pm 22 \%$ despite significantly lower $P F$ ratios $(61 \pm 17 \mathrm{~mm} \mathrm{Hg})$ compared to the remaining studies. In the years 1992 to 1994,5 authors investigated $\mathrm{ECCO}_{2} \mathrm{R}-\mathrm{LFPPV}$ in 79 patients. Average mortality of these patients was $45 \pm 16 \%$ at a $P F$ ratio of $88 \pm 31 \mathrm{~mm} \mathrm{Hg}$. Furthermore, a registryof 7 European centers revealed a mortality of $51 \pm 14 \%$ in 402 patients treated with ECLA. We conclude from our analysis, that ARDS mortality has not changed significantly over the last decades with, a mortality in the $50 \%$ range. Patients seem to benefit from pressure-limited ventilation as well as ECLA.
09

Inhaled nitric oxide in congenital heart surgery-a selective pulmonary vasodilator

Lorint FL, Crupi GC, Sonzogni V, Somaschini M, Ricucci G Department of Anesthesiology II, Neonatal Intensive Care Unit, Department of Cardiothoracic Surgery, Ospedali Riunitz di Bergamo, Bergamo, Italy

Pulmonaryhypertension is associated with increased morbidityand mortality in children after repair of congenital heart disease. The ratio between pulmonary artery pressure $(\mathrm{Pp})$ and systemic artery pressure $(\mathrm{Ps})$ is known to be a major incremental risk factor for the outcome of these patients. The management of this condition is difficult and different types of vasodilators have not succeeded in producing preferential pulmonary vasodilation. In this work we assessed whether inhaled nitric oxide $(\mathrm{NO})$, an endothelium derived relaxing factor, would produce selective pulmonary vasodilarion in pediarric patients with congenital heart diseaseand postoperative pulmonary hypertension. Inhaled NO at 10-15 ppm was used in 22 patients, in the postoperative period, to test the ability in reducing PAP, PVR, transpulmonary gradient, and $\mathrm{Pp} / \mathrm{Ps}$ without any systemic effect. The parients had the following cardiac lesions: tricuspid atresia which underwent Fontan procedure (12), AVSD (5), VSD (3), heart transplant (1), TOF (1). Inhaled NO was started when PAP> $60 \%$ AoP in parientsundergoingbiventricular repair or when transpulmonary gradien $>9 \mathrm{~mm} \mathrm{Hg}$ following Fontan correction or when right ventricular failure was observed. All patients were sedated and under neuromuscular relaxation, ventilated to maintain a $\mathrm{PaCO}_{2}$ of $>2530<\mathrm{mm} \mathrm{Hg}$ with an $\mathrm{FiO}$ of 0.4-0.6. NO decreased PAP from $46 \pm 5$ to $29 \pm 3 \mathrm{~mm} \mathrm{Hg}$ (p<0.05), PVR decreased from $692+30$ to $267 \pm 10$ dyne $\cdot \mathrm{cm}^{-} \mathrm{sec}^{-5}$, Pp/Ps decreased from 0.6 to 0.3 . In the Fontan procedures, it decreased the transpulmonary gradient from $10 \pm 2$ to $6 \pm 1$. CVP, HR and AoP did not change after inhaled NO. In conclusion, inhaled NO at low doses (10-20 ppm) proved to be an ideal selective pulmonary vasodilator after repair of congenital heart lesions. The high morbidity and mortality related to acute pulmonary hypertension can be overcome by the use of nitric oxide.

10

Mechanical assisted circulation—comparison between two different anticoagulation protocols - preliminary results in 45 patients Glauber M, Szefner J, Fiocchi R, Mamprin F, Senni M, Somaschini M, Ferrazzi $P$

Departments of Cardiac Surgery and Neonatology, Ospedali Riuniti, Bergamo, Italy and the Department of Cardiovascular Surgery, Laboratory of Hemostasis, "La Pitie" Hospital, Paris, France

Two anticoagulation protocols were compared in 45 patients mechanically supported either for bridge to transplantation (11), for recovery of myocardial function after cardiac surgery (32) or for acute myocardial infarction (2). In 42 parients a Biomedicus centrifugal pump was used, and in 3 parients a Pierce-Donachyventricles was used. Mechanical support was provided to the left ventricle in 13 parients, to the right ventricle in 4 and to both ventricles in 11 patients; extracorporeal membrane oxygenator (ECMO) support was used in 17 patients. Thirty-three males and 12 females, from 0.2 to 58 years of age, were supported for an average time of 6.0 days (range 1-43). Anticoagulation was based on a continuous infusion of heparin in 27 patients (groupA) or on a multi-system therapy ("La Pitie" protocol) in the remaining ones (group B). This second protocol is based on the contemporaneous administration of dipyridamole (10-25 mg/kg/day), aspirin (1-2 mg/kg/day), heparin (1-2 mg/kg/day) and aprotinin (10,000 kIU/kg/day). Overal mortality was $56 \%$, of which $70 \%(19 / 27)$ in group $A$ and $33 \%(6 / 18)$ in group $B(p<0.05)$. Transplantation and ventricular assist device (VAD) removal was successfully obtained in $59 \%(16 / 27)$ of patients in group $A$ and $89 \%(16 / 18)$ of cases of group $B(p<0.05)$. Bleeding occurred in 15 cases $(55 \%)$ in group $A$ and in 2 cases $(11 \%)$ in group $B(p<0.05)$. Bleeding averaged $266 \pm 218 \mathrm{ml} / \mathrm{kg}$ in group $A$ vs $46 \pm 30 \mathrm{ml} / \mathrm{kg}$ in group $B(p<0.05)$. Surgical revision was needed in 10 patients of group $A$ (mean 1/patient) and in two of group B (mean 0.1/patient) ( $<<0.05)$. Thromboembolic complications were also less frequent with "La Pitie" anticoagulation protocol. It is concluded that thelatter therapy improves the results of conventional heparin infusion. 
11

Initial experience with partial liquid ventilation in nine adult patients with severe respiratory failure

Hirschl RB, Pranikoff T, Wise C, Overbeck MC, Gauger P, Schreiner RJ, Bartlett RH

University of Michigan, Ann Arbor, USA

We evaluated the safery and efficacy of partial liquid ventilation (PLV) (gas ventilation of the perfluorocarbon filled lung) in adult patients with acute respiratory failure on extracorporeal life support (ECLS). Nine adult patients (mean age $30 \pm 10$ years, mean weight $64.9 \pm 6.4 \mathrm{~kg}$ ) were placed on ECLS due to respiratory failure with mean pulmonary shunt fraction $52 \pm 25 \%$. Diagnoses included pneumonia (6), ARDS (1), charcoal aspiration (1), and asthma (1). After 1 to 11 days on ECLS, PLV was initiated using perflubron (LiquiVent ${ }^{\mathrm{TM}}$, Alliance Pharmaceutical Corp.). Doses of $2.5-40 \mathrm{ml} / \mathrm{kg}$ were administered daily for up to 7 days. Radiographic and physiologic parameters were used to guide dosing. Patients were subsequently managed on ECLS and weaned based on gas exchange parameters. Over the first 72 hours following initiation of PLV, mean pulmonary shunt fraction decreased from a baseline of $71 \pm 21$ to $46 \pm 24 \%(p<0.01)$. Simultaneously, pulmonary compliance increased from $12 \pm 11$ to $16 \pm 8 \mathrm{ml} / \mathrm{cm} \mathrm{H}_{2} \mathrm{O}$ ( $\mathrm{p}=\mathrm{NS}$ ). Pneumothorax was observed in one patient, which was possibly related to PLV. Six patients were weaned successfully from ECLS after a mean of 13 days (range 3 22 days) while five survived to discharge and are without evidence of adverse effects. The cause of death in the four patients included progression of lung disease (2), ischemic neuropathy (1), and stroke/ intracranial hemorrhage (1). In conclusion, this initial experience with PLV in adult patients on ECLS serves as a demonstration of the safety and efficacy of this new technique of lung management in the setting of severe respiratory failure.

12

A comparison of perflourocarbon with saline solution for bronchoalveolar lavage in experimental meconium inhalation in guinea pigs

Marraro G, Bonati $M$, Ferrari A, Pagani $C$, Galbiati $A$

Departments of Anesthesia and Intensive Care, Anatomopathology Institute, Fatebenefratelli and Oftalmico Hospital, Laboratory for Mother and Child Health, M. Negri Research Institute, Milano, Italy

Ten guinea pigs were dosed with $1 \mathrm{cc}$ of diluted meconium and subsequently artificially ventilated. After stabilization, 4 underwent bronchoalveolar lavage (BAL) with $5 \mathrm{cc}$ saline solution and 6 with $5 \mathrm{cc}$ of PFC in order to remove the meconium. After lavage the animals were ventilated artificially. Those treated with meconium and washed with saline solution presented a severe worsening of their general condition which led to their dying before the end of the experiment. In those treated with PFC, a reduction of $\mathrm{PaO}_{2}$ was noted after the administration of PFC which then increased progressively. Oxygen saturation presented a slight variation. There was an increase in $\mathrm{paCO}_{2}$ and a reduction in MAP immediately after PFC administration which both rapidly returned to normal. Cardiac rate did not increase significantly and all these animals survived. In aspiration syndrome, the meconium is not spread uniformly throughout the lung but tends to be distributed in the right bronchus and lower right lobe. Some areas are not affected because of their bronchoconstriction. After BAL with saline solution, meconium is more easily distributed and so is more easily absorbed by the lung, worsening lung activity. In the PFC BAL, PFC favors adequate gas exchanges and presents absorption of meconium and facilitates its removal.
13

Partial liquid ventilation-morphologic and histologic aspects in a setting of acute respiratory failure

Quintel M, Heine M, Hirchl RB, Tillmans R, Assmus HP, van Ackern K, Bartlett RH

Departments of Anesthesiology and Pathology, University of Heidelberg, Mannheim, Germany and the Department of Surgery, University of Michigan, Ann Arbor, USA

We evaluated histologic changes during gas ventilation and partial liquid ventilation (PLV) in an adult model of acute respiratory failure. Fourteen sheep $(64.9 \pm 6.4 \mathrm{~kg})$ underwent oleic acid lung injury followed either bygasventilation (7) or partial liquid ventilation (7) urilizing perflubron (LiquiVent ${ }^{\mathrm{TM}}$, Alliance Pharmaceutical Corp., San Diego, USA). According to astandardized protocol, specimens of 12 different regions of the lung were taken. Hematoxylin-eosin stained paraffin sections of 5-8 $\mu$ were used for further analysis. We developed a semiquantiative scoring system to describe the extent of the lung injury. The following histologic features were analyzed-hyperemia, granulocyte sticking, thrombocytic aggregation, fibrin deposition, perivascular and alveolar edema, lymphangectasia, alveolarhemorrhageand hyalinemembranes. Thescorevalues represented the extent of lung injury or diffuse alveolar damage (DAD) and were statistically tested. Parrial liquid ventilated animals showed significant better results in overall score values $(\mathrm{p}=0.015)$. Pulmonary hyperemia $(\mathrm{p}=0.008)$ and alveolar edema $(\mathrm{p}=0.003)$ were significandy decreased. In addition, selective evaluation of ventral versus dorsal values showed for both regions significant decreased values for partial liquid ventilated animals (PLV) compared to gas ventilated (GV) animals. Thesehistologicchanges wereassociated with adistinct improvementingasexchangeduringthestudyperiod. $\mathrm{PaO}_{2}$ increasedsignificantly (GV $39.8 \mathrm{~mm} \mathrm{Hg}, \mathrm{LV} 107.5 \mathrm{~mm} \mathrm{Hg}, \mathrm{p}=0.0049$ ) and SvO (GV 25.7\%, LV $63.1 \%, \mathrm{p}=0.01$ ). We condude that in thisoleic acid model oflung injury, partial liquid ventilation with perflubron leads to a distinct decrease of characteristic histomorphologic pulmonary alterations. This evidence for reduced lung injury cannot be traced back to the well known $\mathrm{PFOB}$ properties alone and makes the speculated property as an antiinflammatory agent very likely.

14

Inhaled nitric oxide versus inhaled prostacyclin in acute respiratory failure with pulmonary hypertension—an experimental study

Zobel G, Dacar D, Röll S, Friehs I, Kuttnig-Haim M, Urlesberger B, Riccabona $M$, Reiterer $F$, Maurer $U$

ECMO-Center Graz, University of Graz, Graz, Austria

To compare oxygenation and pulmonary hemodynamics between inhaled $\mathrm{NO}$ and inhaled $\mathrm{PGI}_{2}$ in acute respiratory failure with pulmonary hypertension was induced in twelve piglets weighing 9 to 12 $\mathrm{kg}$ by repeated lung lavages and a continuous infusion of the stable endoperoxane analogue of thromboxane. Thereafter the animals were randomly assigned either for $\mathrm{NO}$ or $\mathrm{PGI}_{2}$ application. All animals were treated with different concentrations of NO or different doses of $\mathrm{PGI}_{2}$ Continuous monitoring included ECG, CVP, MPAP, MAP, $\mathrm{SaO}_{2}$ and $\mathrm{SvO}_{2}$ measurements. NO inhalation of $10 \mathrm{ppm}$ resulted in a significant increase in $\mathrm{PaO} / \mathrm{FiO}$ from $7.8 \pm 1.34$ to $46.1 \pm 9.7 \mathrm{kPa}$. Whereas MPAP decreased significantly from $5.1 \pm 0.26$ to $3.7 \pm 0.26 \mathrm{kPa}$ during inhaled NO of $40 \mathrm{ppm}, \mathrm{MAP}$ did not change. Inhaled $\mathrm{PGI}_{2}$ significantly increased $\mathrm{PaO}_{2} / \mathrm{FiO}_{2}$ from $7.4 \pm 0.6$ to $32.4 \pm 3.1 \mathrm{kPa}(\mathrm{p}<0.01)$. $\mathrm{PGI}_{2}$ aerosol delivery did not change HR, MAP and CVP. However, a significant decrease in MPAP and PVR by $22 \%$ and $36 \%$, respectively, $(\mathrm{p}<0.05)$ was observed. In conclusion, inhaled $\mathrm{NO}$ and inhaled $\mathrm{PGI}_{2}$ act as selective pulmonary vasodilators in acute respiratory failure with pulmonary hypertension resulting in improved oxygenation mainly due to improved mismatch of pulmonary perfusion and ventilation. 
15

Venovenous extracorporeal membrane oxygenation and independent lung apneic oxygenation for giant pneumatoceles following hydrocarbon ingestion in a three-year-old child

Dejode JM, Pillon P, Soula F, Lagier P, Vialet R, Durandy Y, Kittel J, Martin $C$

Department of Anesthesia and Intensive Care, Centre HospitaloUniversitaire Nord, Marseilles, France

Hydrocarbon ingestion is a rare cause of acute lung injury, and the most severe complication is the development of giant pneumatoceles. If mechanical ventilation is needed, barotrauma facilitates this complication. We report the case of a 3-year-old infant who survived this insult with venovenous (VV) extracorporeal membrane oxygenation (ECMO) and apneic ventilation. A single lumen catheter placed in right atrium after introduction in the right jugular vein permitted collection and reinjection of blood through an alternating clamp. During apneic ventilation (mean airway pressure $[\mathrm{P}]=10 \mathrm{~cm}$ of $\mathrm{H}_{2} \mathrm{O}$ ), a giant pneumatocele (diameter $12 \mathrm{~cm}$ ) of the right lung developed, and together with an alveolar collapse of the left lung, was responsible for severe anoxia. The use of apneic oxygenation with independent lung ventilation ( $\mathrm{P}_{\mathrm{aw}}=6 \mathrm{~cm}$ of $\mathrm{H}_{2} \mathrm{O}$ on the right lung and $\mathrm{P}_{\mathrm{aw}}=20 \mathrm{~cm}$ of $\mathrm{H}_{2} \mathrm{O}$ on the left lung) resulted in a dramatic reduction in size of the pneumatocele, with a secondary expansion of the left lung. After 14 days of VVECMO therapy, blood gases were dramatically improved. However, 16 days after VV ECMO was stopped, a new giant pneumatocele of the right lung occurred. The independent lung mechanical ventilation was started again for 2 days. The child was extubated 28 days after VV ECMO and in good clinical status. This combined therapy associating VVECMO and apneic oxygenation with independent lung ventilation is original and effective. The combination of VV ECMO (to improve gas exchange) and independent lung apneic ventilation (to modulate airway pressure on each lung) could be considered in case of asymmetrical lung damages caused by lung barotrauma.

16

Neonatal extracorporeal membrane oxygenation in Austria-19901994

Kuttnig-Haim M, Reiterer F, Zobel G, Dakar D, Maurer $U$, Urlesberger B, Riccabona M, Kerbl R, Müller W ECMO-Center Graz (Departments of Neonatology, Pediatrics, and Cardiac Surgery), University of Graz, Graz, Austria

From 1990 to 1994, 22 neonates (10 females, 12 males) underwent extracorporeal membrane oxygenation (ECMO) using a pressure controlled roller pump system (Stöckert) and a silicone membrane lung (Scimed). Mean birth weight was $3,149 \pm 57.4 \mathrm{gm}$, mean gestational age $39.3 \pm 6.4$ wks. Pulmonary conditions leading to ECMO were MAS $(n=9), P P H N /$ septicemia $(n=9)$, idioparhic PPHN $(n=4)$. Mean time on the ventilator (BL 8000) before ECMO was 5.0 days (range 0.5-17 days). Mean oxygenation parameters and ventilator settings prior to ECMO: OI 42.2 $23.1, \mathrm{AaDO}_{2} 620 \pm 5.1 \mathrm{~mm} \mathrm{Hg}$, PIP $45 \pm 1.9 \mathrm{~cm} \mathrm{H}_{2} \mathrm{O}$,

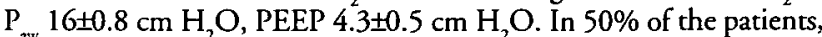
$\mathrm{ECMO}$ was performed in the venoarterial mode (VA), in the other $50 \%$ in the venovenous mode (VV). One patient was switched from VA to VV due to long-term perfusion. Mean duration of ECMO was 9.3 days (range 3-30 days). We performed pulmonary function testing including FRC measurements using a computerized system (PEDS) to assist in weaning from ECMO. Following ECMO, patients were ventilated for $9.7 \pm 2.8$ days and stayed in the ICU for a total of $25.6 \pm 5.1$ days. Overall survival rate in the 5 -year-period was $77 \%$; in 1994, 6 out of 7 parients survived (85.7\%). Among the survivors, 2 patients suffered from mild BPD without the need for home oxygen supply. Neurological followup $(4,8,12$ months of age, then once a year) showed one patient having severe cerebral palsy and two patients being slightly mentally retarded (overall handicap rate $17.6 \%$ ). Patients on the VA-bypass had reconstruction surgery of the carotid artery using a special method. All of these 11 patients showed sufficient perfusion of the right carotid artery on Doppler sonographic follow-up examinations.
17

Venoarterial extracorporeal membrane oxygenation in infants and children

Gentili M, Gentili S, Pagni R

PICU, NICU, ECMO Center, "Salesi" Children's Hospitah, Ancona, Italy

We have carried out extracorporeal lung support for the treatment of acute respiratory failure unresponsive to optimal therapy in our pediatric and neonatal intensive care unitsince October 1990 . Wehaveconsidered as entry criteria for ECMO: $\mathrm{AaDO}_{2}$ over $600 \mathrm{~mm} \mathrm{Hg}$ for more than six hours; oxygenarionindex $\left(\mathrm{FiO} \cdot \mathrm{MAP} / \mathrm{paO}_{2}\right.$ )greaterthan 0.4 . Inour unit, venoarterial (VA) bypass (right jugularvein to right carotid artery) has been chosen because it permits us to supply cardiac support if required. We are used to repairing the carotid artery after ECMO. Blood flow is maintained at a rate of 80-100 $\mathrm{cc} / \mathrm{kg} / \mathrm{min}$ and isgradually decreased aslungfunction improves. Hemoglobin is kept in the range of $14-16 \%$ and the hematocrit in the range of $42-45 \%$. At the beginning of bypass, we immediately decreaseventilator setting to non-

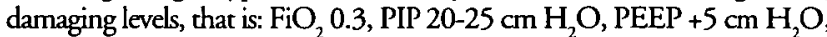
$\mathrm{RR} 10 / \mathrm{min}$. Anticoagulation is obtained with constant infusion of heparin, after a loading dose of $30 \mathrm{U} / \mathrm{kg}$, to have an activated clotting time of $185 \pm 5$ seconds. We maintain platelet count more than 100,000 . Venous and arterial saturation, $\mathrm{pH}, \mathrm{pO}_{2}, \mathrm{pCO}_{2}$ are monitored on-line. Pulse-oximetry is carried out continually; this permirs us to reduce systemic blood samples to $6-8$ hours intervals. To cannulate the internal jugular vein and the common carocid artery, we employ Elecath catheters of different sizes according to the weight of the patient. The extracorporeal circuit is composed of a vortex pump, a membrane oxygenator (Scimed 0.8), a heat exchanger and a silicon rubber collapsible bladder. Since October 1990, 10 patients underwent ECMO. Four patients presented MAS, one MAS+PPHN, one CDH, one HMD, three viral pneumonia. The survival rate was $50 \%$. At follow-up, the five surviving patients have normal respiratory clinical features, satisfactory neurological development and Doppler echocardiography showed normal flow in the right common carotid artery.

18

Extracorporeal membrane oxygenation at Rikshospitalet, Oslo 1989-1985-analysis of 18 cases

SvennevigJL, Pedersen T, Østbak RW, Geiran O, Skeie B, Sponheim S Department of Surgery $A$ and Department of Anesthesiology, Rikshospitalet, Oslo, Norway

From September 1989 through January 1995 a total of 18 patients have been treated with extracorporeal membrane oxygenation (ECMO)11 males and 7 females, age range 0 to 59 years (mean 14.22). Ten patients were discharged alive and are well, 1 month to 3 years after treatment. Five patients were treated because of severe postcardiotomy heart failure, 2 were successfully transplanted, 1 recovered and 2 died. Three patients were treated because of lung insufficiency due to RS-virus infection (all survived), congenital diaphragmatic hernia (2, none survived), trauma (1, died), meconium aspiration (2, both survived), p.o. aspiration ( 1 , died) abdominal infection (1, survived), lung $\mathrm{tx}$ ( 1 , died) intoxication ( 1 , died), Wegners granulomatosis ( 1 , survived). Survival was associated with age $(p=0.01)$, not with gender, days on $\mathrm{ECMO}$ or mode of cannulation. In conclusion, our first experiences with ECMO have been promising both for cardiac as well as for lung support. 
19

Experience with extracorporeal lung support in the treatment of severe acute respiratory distress syndrome

Lasch P, Varnholt V, Suske G, Kachel W, Wirth $H$

Kinderklinik and Kinderchirurgische Klinik, Mannheim, Germany

Since 1989, with experienced advances in the treatment for severe acute respiratory distress syndrome (ARDS), extracorporeal membrane oxygenation (ECMO) has been used in the therapy of 28 children (aged 0.1 10 years) with refractory respiratory failure due to a variety of underlying disorders in our institution. All were considered to have potentially reversible problems and to have received maximal conventional treatment (including NO-inhalation and HFOV). When starting ECMO, all patients were in a progressive decline on high pressure ventilation (mean OI 49.8, mean MAP $23.5 \mathrm{~cm} \mathrm{H2O}$ ) and high $\mathrm{FiO}_{2}$ (usually, $\mathrm{FiO}_{2}$ 1.0). ECMO was mainly venovenous. In 1 patient ECMO was started venoarterial; in another patient we changed from VV to VA bypass. Fifteen patients (54\%) survived the acute illness, running on ECMO for a mean of 137 hours without severe chronic pulmonary or neurological sequelae. Thirteen patients died (after a mean time on ECMO of 377 hours) while on or shortly after ECMO. The problem of case selection for ECMO remains and is controversial. In our series, the duration of hypoxemia and excessive ventilatory support before starting ECMO were no discriminating parameters to project the success or the failure of ECMO. Only the small group of immunocompromised children seem not to benefit from extracorporeal life support.

\section{1}

Neonatal extracorporeal membrane oxygenation-the Czech experience Nekvasil R, Penkova Z, Vasek L, Piler P, Bobula A, Novotna E, Pavlicek $V$, Hnilicka $M$

NICU and ECMO Center and Department of Pediatric Surgery, Children's Hospital, Brno, Czech Republic

In spite of the fact that neonatal ECMO has been gradually considered a standard method of solving uncontrollable respiratory failure in newborns in most countries of western Europe, the introduction of this sophisticated method in countries of the former communist block meets a lot of problems. In the course of two years, only 16 newborns, birth weight 2,000-4,300 gm, were referred to neonatal ECMO because of uncontrollable respiratory failure. On admission, the average values of oxygenation index were $51 \pm 12$, and $\mathrm{AaDO}_{2} 79.6 \pm 7.6 \mathrm{kPa}$. Four newborns $(25 \%)$ died shortly after admission or during transport without possibility for further intervention. Five newborns $(31.3 \%)$ were treated using high-frequency ventilation (HFO or HFJV), one for conspicuous airway resistance paradoxically with low-frequency IPPB. All ventilated newborns survived. ECMO was applied in 6 newborns (37.9\%), and 3 survived. The mortality rate was $44 \%$. In conclusion, the fact that in the Czech Republic (10 million population with birth rate of about 100,000 newborns/year) only a small part of patients was referred to neonatal ECMO has a number of causes. The most important is ignorance of prognostic and indication criteria at forwarding workplaces and the aversion of neonatologists to all new therapeutic interventions. Last but not least, a negative role is also played by current change of heal th service systems when, under the influence of health-service insurance companies, a newborn in serious condition given only a standard intensive care in primary and secondary NICU is literally "the Golden Calf," and therefore, these workplaces either do not send him or send him too late to an ECMO Center.

22

Pediatric ECMO-the Czech experience

Nekvasil R, Penkova Z, Vasek V, Cundrle I, Fedora M, Piler P, Bobula $A$, Pavlicek $V$, Novotna E, Hnilicka $M$ NICU and ECMO Center and Department of Pediatric Surgery, Children's Hospital, Brno, Czech Republic

Even though the number of pediatric patients treated with ECMO is less than a hundred a year-according to both EESO and ELSO registry, mortality is considerable-pediatric ECMO has been the last attempt at managing fulminant respiratory failure. Eight children, aged 2 month-18 years, were referred for pediatric ECMO because of uncontrollable respiratory failure. Before connecting to bypass, the attempt at optimizing conventional mechanical ventilation (Bicore Monitoring System, Irvine, CA) was made. As the conventional ventilation failed in all cases, the next step was the attempt at improving oxygenation and clinical condition using high-frequency jet (HFJV) or oscillatory ventilation (HFO). Due to failure of these methods, venovenous ECMO combined with apneic oxygenation and low-frequency ventilation (LFPPV) was indicated. Four patients were treated by HFO and 3 of them survived. One patient showed conspicuous improvement of both oxygenation and carbon dioxide elimination; however, he was disconnected from the oscillator due to brain death. One patient died shortly after admission without any possibility of intervention. Three patients were connected to venovenous ECMO, two survived at combined application of $5 \mathrm{ppm} \mathrm{NO}$ and ECMO. Although oxygenation was improved at the decrease of inflation pressures of LF-PPV in the last patient, ECMO was terminated after 16 hours because of mechanical complications and the patient died later. In conclusion, no child should die from isolated respiratory failure in the last decade of this century without even brief consideration of using ECMO therapy. 
23

The influence of lung injury due to mechanical ventilation on the initiation of extracorporeal membrane oxygenation

Bartsch H, Kossel H, Philippi W, Eyrich K, Versmold H, Waldschmidt J Interdisciplinary ECMO-Group, Benjamin Franklin University Hospital, Berlin, Germany

Before entry criteria for extracorporeal membrane oxygenation (ECMO) are met, newborns may require aggressive mechanical ventilation which may result in lung injury. Case report-a 2-day-old newborn with meconium aspiration was transferred to our hospital for ECMO therapy. Using conventional mechanical ventilation, the child remained hypoxic with a maximum arterial $\mathrm{paO}_{2}$ of $46 \mathrm{~mm} \mathrm{Hg}$. With high-frequency-oscillatory ventilation the $\mathrm{paO}_{2}$ improved to $71 \mathrm{~mm} \mathrm{Hg}$. However, due to the aggressive ventilatory requirements, repeated pneumothoraces and bronchopleural fistulae developed. With an oxygenation index greater than 40, ECMO was commenced and this therapy was continued for 4 days. A few hours following the discontinuation of ECMO, a recurrence of the bronchopleural fistulas occurred which required surgical intervention and closure of the defects. After 5 days of conventional ventilation, extubation could be performed. In meeting the entry criteria for ECMO, conventional mechanical ventilation increases the risk of severe lung injury. The lung injury resulting from mechanical ventilation and the presence of a pneumothorax seem to play an important role in the prognosis even before the entry criteria for ECMO are artained $(\mathrm{OI}<40)$. Of the 18 newborns transferred to our hospital for $\mathrm{ECMO}$, 7 newborns (39\%) were treated with ECMO. Eight of the 18 newborns (44\%) developed a pneumothorax with conventional ventilation and 5 of these 8 newborns (63\%) subsequently required ECMO. In the situation where adequate oxygenation cannot be obtained with mechanical ventilation and more aggressive ventilation leads to severe lung injury, ECMO should be considered even if the $\mathrm{OI}$ is below 40 . In addition to preventing irreversible tissue damage due to hypoxia, severe lung injury due to aggressive mechanical ventilation should be avoided.

24

High frequency oscillatory ventilation-an alternative therapy to apneic oxygenation during venovenous extracorporeal membrane oxygenation for severe meconium aspiration syndrome

Dejode JM, Nicaise C, Pillon P, Lagier P, Soula F, Vialet R, Aubry C, Lando A, Martin C

Department of Anesthesia and Intensive Care, Centre HospitaloUniversitaire Nord, Marseilles, France

Meconium aspiration syndrome (MAS) is a frequent cause of respiratory distress in the neonate. It is accompanied by a high rate of persistent pulmonary hypertension. The improvement in oxygenation after ECMO treatment is caused by diminished pulmonary hypertension, reversal of rightto-left shunting, and improved pulmonary capillary blood flow, rather than an improvement in lung mechanics. We describe the case of a newborn who survived this insult with venovenous (VV) ECMO and high frequency oscillatory ventilation (HFOV). VVECMO was established for hypoxemia (arterial oxygen saturation $80 \%$, arterial partial pressure of oxygen $\left[\mathrm{PaO}_{2}\right] 45$ $\mathrm{mm} \mathrm{Hg}$ ), barotrauma (pulmonary interstitial emphysema) and hemodynamic insufficiency (mean arterial blood pressure $40 \mathrm{~mm} \mathrm{Hg}$ ) under HFOV (mean airway pressure $\left[\mathrm{P}_{\mathrm{z} w}\right] 20 \mathrm{~mm} \mathrm{Hg}$, frequency $15 \mathrm{~Hz}$, peak-to-peak 80 $\mathrm{mm} \mathrm{Hg}$, fractional inspired concentration of oxygen $\left[\mathrm{FiO}_{2}\right] 1.0$ ) vasoactive drugs (epinephrine $0.3 \mu \mathrm{g} / \mathrm{kg} / \mathrm{min}$, dopamine $35 \mu \mathrm{g} / \mathrm{kg} / \mathrm{min}$, dobutamine 15 $\mu \mathrm{g} / \mathrm{kg} / \mathrm{min}$ ) and inhaled nitric oxide (20 parts per million by volume). A single lumen catheter, placed in the right atrium after introduction in the right jugular vein, permitted collection and reinjection of blood through an alternating clamp. The adjustment of HFOV at start of VV ECMO was: $\mathrm{FiO}_{2} 0.8, \mathrm{P} 14 \mathrm{~mm} \mathrm{Hg}$, peak-to-peak $22 \mathrm{~mm} \mathrm{Hg}$, frequency $16 \mathrm{~Hz}\left(\mathrm{PaO}_{2}\right.$ $65 \mathrm{~mm} \mathrm{Hg}$ ). Usually, in our ICU, VV ECMO is associated with apneic oxygenation. However, because of the suspected airway obstruction caused by MAS, a combination of VV ECMO and HFOV was selected. The duration of VV ECMO was 5.75 days. This child was discharged from ICU after 15 days. A study evaluating lung mechanics after the combination $\mathrm{VV}$ $\mathrm{ECMO} / \mathrm{HFOV}$ should be undertaken.
25

Surgical repair of congenital diaphragmatic hernia during extracorporeal membrane oxygenation-hemorthagic complications and the effect of tranexamic acid

von den Staak F, Geven W, Festen C

Academic Children's Surgical Centre, University Hospital St. Radboud, Nijmegen, The Netherlands

Since extracorporeal membrane oxygenation (ECMO) became available in our institution (January 1991), it has been incorporated into a protocol of preoperative stabilization and delayed repair for congenital diaphragmatic hernia $(\mathrm{CDH})$. If ECMO was necessary for stabilization, surgical repair of the diaphragmatic defect was performed during ECMO. In the beginning we encountered significant postoperative bleeding complications at the surgical site, due to the general heparinization. For that reason, we adopted the use of tranexamic acid (TEA), an antifibrinolytic agent, during and after $\mathrm{CDH}$ repair on ECMO (since January 1993). In this study, we try to evaluate the effect of TEA. In the first period (1991-1992: n=9), ECMO support was stopped postoperatively in 5 of the 9 patients following surgical $\mathrm{CDH}$-repair because of severe bleeding at the surgical site. Exploration of the surgical site was necessary in one patient because of bleeding. In the second period (19931994: $\mathbf{n}=6$ ) we used TEA. In no patient was ECMO support withdrawn abruptly for bleeding. Patients receiving TEA had significantly less bleeding at the surgical site and had fewer red blood cell (RBC) transfusion requirements than patients not receiving TEA. However, we observed severe thrombotic complications in the very first 2 parients of the TEA-group. In 2 other parients of the TEA-group, we observed cloting in the bridge of the VAECMO-circuit. TEAseems effectivein reducing postoperativeblood loss and hemorrhagic complications associated with $\mathrm{CDH}$-repair on ECMO. TEA especially an overdose of TEA, can be responsible for severe thrombotic complications; the appropriate dosage of TEA for $\mathrm{CDH}$-repair during ECMO seems to be one bolus of $10 \mathrm{mg} / \mathrm{kg}$ TEA intravenously $30 \mathrm{~min}$ prior to the anticipated CDH-repair and a continuous infusion of $1 \mathrm{mg} / \mathrm{kg} / \mathrm{hr} 24$ hours following $\mathrm{CDH}$-repair.

26

Application of a new anticoagulant-Nafamstat Mesilateto control hemorrhagic complications during extracorporeal membrane oxygenation

Nagaya M, Murabashi O, Kato J, Niimi $N$

Department of Pediatric Surgery, Central Hospital, Aichi Prefectural Colony, Kasugai, Japan

Heparin is traditionally used to elongate the activated clotting time (ACT) during ECMO practice. In some cases, however, particularly in patients suffering from hemorrhagic complications, it is desirable to maintain a lower ACT value. The ideal status, if possible, would be to make a discrepancy between ACT values of the patient and the ECMO circuit, and to decrease the value of the patient. To achieve this status, we are using a new anticoagulant, Nafamstat Mesilate (FUT) in order to decrease the heparin doses. FUT is a synthetic protease inhibitor and very rapidly metabolized. Six newborns (CDH 3; MAS 1; sepsis 2) in whom hemorrhagic complications occurred at various sites, were selected to use FUT. FUT was infused through a different route from heparin on the venous line of the ECMO circuit. In all cases except one, the doses of heparin were decreased following the addition of FUT, and in the other case, FUT was solely used. Blood samples were simultaneously drawn from both venous and arterial lines, and their ACTs were measured (Hemochron). The ACT value of the arterial line was maintained at the same level as before FUT administration. The average dose of heparin was $19.3 \mathrm{IU} / \mathrm{kg} / \mathrm{h}$ (range 11.4 to 24) and that of FUT $0.57 \mathrm{mg}$ $\mathrm{kg} / \mathrm{h}$ (range 0.39 to 1.11 ). In thecase for whom FUT was solely used, the doses was $6.64 \mathrm{mg} / \mathrm{kg} / \mathrm{h}$. The average ACT value of the arterial line was $218.8 \mathrm{sec}$ (range 203 to 250), and that of the venous line was $185.8 \mathrm{sec}$ (range 164 to 205). The average difference between both lines was $33.0 \mathrm{sec}$ (range 20 to 44). In conclusion, FUT helped to produce a difference between ACT values of the patient and the ECMO circuit. If about $20 \mathrm{IU} / \mathrm{kg} / \mathrm{h}$ of heparin and 0.5 $\mathrm{mg} / \mathrm{kg} / \mathrm{h}$ of FUT is administered, about 30 sec of difference can be made in the ACT values between venous and arterial lines. 
27

Activation of the clotting system during neonatal extracorporeal membrane oxygenation

Urlesberger B, Zobel G, Kuttnig-Haim M, Maurer U, Reiterer F, Riccabona M, Dacar D, KerblR, Leschnik B, Muntean W ECMO-Center Graz (Departments of Neonatology, Pediatrics, and Cardiac Surgery), Universtty of Graz, Graz, Austria

The aim of this study was to determine the degree of clotting activation under the usual anticoagulation regimen with systemicheparinization. TheECMO perfusion circuit consisted of a roller pump, silicone membrane lungs and silicon rubber tubings. Coagulation was controlled routinely twice a day by measuring prothrombin time, partial thromboplastin time, thrombin time, fibrinogen, antithrombin III and reptilase time. Platelet counts were done on demand, at least twice a day. In addition the following specific markers of activation of the clotting system were measured: prothrombin activation fragment $1+2\left(\mathrm{~F}_{1+2}\right)$, thrombin-antithrombin III complexes (TAT), and Ddimer. Measurements were done before ECMO-start, after 5 minutes run, at hours 1, 2, 3, 4, 6, 12, 24, and 48 after ECMO start. All seven infants included into this study showed excessively high levels of clotting activation markers within the first two hours of ECMO: $F_{1+2} \quad 11.6 \pm 0.9 \mathrm{nmol} / \mathrm{l}$ $($ mean + SEM); TAT $920 \pm 2.2 \mu \mathrm{g} / \mathrm{l}$; D-dimer $15522 \pm 3689 \mathrm{ng} / \mathrm{ml}$. In the following 46 hours of ECMO, $\mathrm{F}_{1+2}$ and TAT showed a decrease, whereas $\mathrm{D}$ dimer did not. In the first 24 hours of ECMO there was seen furthermore a decrease of fibrinogen, of prothrombin time (representing the consumption of factor II, V, DX, X and fibrinogen), and a steep decrease of platelets. These findings were consistent with the pattern of consumptive coagulopathy, which seemed to improve after 24 hours. At this time the need for substitution of platelets and fibrinogen decreased, prothrombin time improved and TAT and $\mathrm{F}_{1+2}$ showed decreasing tendencies. No negative clinical effects of this consumptive coagulopathy could be observed in our "standard" neonatal ECMO patients. This rises the question how stable this situation is, and what happens in infants with latent DIC due to sepsis?

28

Determination of cannula position during extracorporeal membrane oxygenation with chest $\mathrm{X}$-ray

Nieuwenhuis J, von den Staak F, de Jong J, Tanke R, Festen C Academic Children's Surgical Centre, University Hospital St. Radboud, Nijmegen, The Netherlands

Between 1989 and December 1994, 53 parients were treated with venoarterial ECMO. To determine the position of the arterial and venous cannula a chest $\mathrm{X}$-ray was used, both after cannulation and during ECMO. To review this method we assessed the position of the cannulas in relation to the vertebral column. The position of the venous cannula varied from VTh (thoracic vertebra) 6 to VTh 11 , the arterial cannula from VC (cervical vertebra) 6 to VTh 6 . The position of the cannulas varied from day to day. This 'traveling' took placeovera distance of one to fourvertebras; venouscannula: $33.3 \%$ over 1 vertebra; $51.0 \%$ over $2 ; 13.7 \%$ over 3 and $2.0 \%$ over 4 ; arterial cannula: $56.9 \%$ over $1 ; 39.2 \%$ over 2 and $3.9 \%$ over 3 vertebras. Looking at the difference in placement of the cannulas after cannulation and the first chest $\mathrm{x}$-ray during ECMO, only $26.7 \%$ of the venous and $11.1 \%$ of the arterial cannulas were at the same spot, where they were placed at cannulation $(37.8 \%, 42.2 \%$ lying on a higher and $36.6 \%, 46.7 \%$ lying on a lower spot, respectively). Malposition of the cannulas was demonstrated by ultrasound investigation ( $17.1 \%$ for the venous and in $6 \%$ for the arterial cannula). We tried to find a relation between a certain place of the cannulas according to chest X-ray and the quality of ECMO-flow. We analyzed in all patients the maximum flow per kilogram, the birth weight, the cumulative fluid balance, the cannula sizes and the amount of GPO given (as an indication for insufficient venous return). No relations were found, so no qualitative judgement could be given to a certain place of the cannulas. In conclusion, 1) there is agreat difference in cannula position, both inter-as intra-individual; 2) chest $\mathrm{x}$-ray is not a good method for assessment of the cannula position; 3) therefore a chest $\mathrm{X}$-ray to determine cannula position during cannulation seems to be superfluous; and 4) malposition of the cannulas can be demonstrated by echocardiography during which correction of the malposition is possible.
29

Changes in inflammatory mediators and total body water during extracorporeal membrane oxygenation

Underwood MJ, Pearson GA, Waggoner J, Elliot MJ, Firmin RK Departments of Cardrac Surgery, Bristol Royal Infirmary, Groby Road Hospital, Leicester and Great Ormond Street, London, UK

Extracorporeal membrane oxygenation (ECMO) used for the management of respiratory failure may result in a whole body inflammatory response which may lead to capillary leak, al though this has not been widely investigated. We studied 6 patients ( 5 pediatric, 1 neonate) treated with $\mathrm{ECMO}(2 \mathrm{VA}, 4 \mathrm{VV}$ ages 0.25-71 months [mean 26], weights 4.01-25 kg [mean 11.7]). Blood samples were taken before instigation of ECMO, 4, 12 and 24 hrs post$\mathrm{ECMO}$ and daily for 6 days. Free radical activity $(\mathrm{FR})$ was quantified using the oxidized IgG Fl/UV ratio. Neutrophil elastase (NE) and interleukin-8 (IL8) levelswere measured by ELISA assays. Changes in total body water were assessed using a previously validated electrical bioimpedance method. Statistical analysis was made using repeated measures analysis of variance and t-test where appropriate. FR activity significantly increased $4 \mathrm{hrs}$ after instigation of $\mathrm{ECMO}(\mathrm{IgG} \mathrm{Fl} / \mathrm{UV} 32.1 \pm 3.2$ (values are mean $\pm \mathrm{SE}$ ) from 24.1 \pm 3.0 , $\mathrm{p}=0.0005$ ) and remained elevated during the 6 days trearment. NE also significantly increased by $4 \mathrm{hrs}$ (mean $94.8 \pm 8.9$ to $678 \pm 153.4 \mu \mathrm{g} / \mathrm{l}, \mathrm{p}=0.005$ ) but had returned to pre-ECMO values by day 6 . IL 8 levels also rose after $\mathrm{ECMO}$ (from $98 \pm 39$ to $246 \pm 117.4 \mathrm{pg} / \mathrm{ml}$ ) al though no statistical difference was noted over time due to the large variation between subjects ( $p=0.009$ ). TBW (expressed as percentpre-ECMO bodyweight) significantly fell during treatment with ECMO by 24 hrs (from 1 18.6 12.6 to $96.5 \pm 8.2, \mathrm{p}=0.0004$ ). No other changes were noted. This study demonstrates that ECMO stimulates an inflammatory response to extracorporeal perfusion (increased FR, NE) but despite this, treatment results in a significant reduction in total body water. The complex relationship between the inflammatory response to extracorporeal perfusion and its effect on tissue edema merits further investigation.

30

Circulatory changes during extracorporeal membrane oxygenation de JongJ, Tanke R, Festen $C$

Academic Children's Heart Centre, University Hospital St. Radboud, Nijmegen, The Netherlands

Between 1989 and 1993, 42 neonates were treated with extracorporeal membrane oxygenation (ECMO) for several indications such as congenital diaphragmatic hernia $(34.1 \%)$, meconium aspiration syndrome $(31.7 \%)$, primary pulmonary hypertension of the neonate $(4.9 \%)$, respiratory distress syndrome $(4.9 \%)$ and sepsis $(24.4 \%)$. The mean survival was $78 \%$. Prospectively, every patient was investigated before ECMO for tricuspid insufficiency (TI), right-to-left/left-to-right (R-L/ L-R) shunting and systolic time intervals using echocardiography (Toshiba SSH-140A). TI was found in 14 patients (33\%), of which $43 \%$ died. In the group with no $\mathrm{TI}$, only $17 \%$ died. Using the Bernoulli's equation, we calculated right ventricular (RV) pressure. Atrial R-L shunting was demonstrated in 11 patients (26\%) and ductal R-L shunting also in 11 patients (26\%). Before ECMO, the mean systolic time intervals for respectively left ventricle (LV) and RV were 0.40 and 0.49 . In 20 patients we looked retrospectively for changes in shunt pattern and systolic time intervals. Ductal L-R shunting was demonstrated in 6 patients during ECMO, whereas only one patient showed this type of shunting before ECMO. R-L shunting disappeared in almost all, except 2 patients. The mean systolic time interval for $\mathrm{LV}$ decreased to 0.31 and for $R V$ to 0.29 . The shortening fraction decreased from $35 \%$ before ECMO to $26 \%$ during ECMO. In conclusion, $\mathrm{TI}$ is seen in only one-third of neonates prior to ECMO. During ECMO, R$\mathrm{L}$ shunting disappeared in almost all patients in contrast to ductal $\mathrm{L}-\mathrm{R}$ shunting which shows a remarkable increase. Serial Echo-Doppler investigations are an excellent method for monitoring circulatory changes during ECMO. 
31

Venous oxygen saturation and other biochemical parameters during progressive hypoxia in 10-day-old piglets

van der Hoeven MAHBM, Maertzdorf WJ, Blanco CE

Department of Neonatology, University Hospital, Maastricht, The Netherlands

Venous oxygen saturation $\left(\mathrm{SvO}_{2}\right)$ reflects the residual oxygen after tissue oxygen extraction and represents the combined sufficiency of arterial oxygen saturation $\left(\mathrm{SaO}_{2}\right)$, cardiac output $(\mathrm{Qt})$, hemoglobin $(\mathrm{Hb})$ and tissue oxygen consumption $\left(\mathrm{VO}_{2}\right)$. To study the changes of $\mathrm{SvO}_{2}$, we induced progressive hypoxia in 10-day-old anesthetized ventilated piglets by different oxygen/nitrogen mixtures. $\mathrm{SvO}_{2}$ was measured continuously by a fiberoptic catheter (Oximetrix, Abbott Laboratories) in the pulmonary artery. Aortic flow $(\mathrm{Qt})$, arterial and venous blood gases, hemoglobin, lactate and pyruvate were measured. Oxygen delivery $\left(\mathrm{DO}_{2}\right), \mathrm{VO}_{2}$ (Fick equation), fractional oxygen extraction (FOE) $\left(\mathrm{VO}_{2} / \mathrm{DO}_{2}\right)$, lactate/pyruvate ratio and change in lactate concentration (change Lact) were calculated for each period of stable arterial oxygen saturation $\left(\mathrm{SaO}_{2}\right)$.

\begin{tabular}{|c|c|c|c|c|c|}
\hline $\mathrm{SaO}_{2}(6)$ & $983 \pm 1.1$ & $917 \pm 32$ & $769 \pm 76$ & $489 \pm 62$ & $22.8 \pm 7.1$ \\
\hline $\mathrm{CaO}_{2}(\mathrm{~m} / \mathrm{l})$ & $129 \pm 2.3$ & $111 \pm 19$ & $100 \pm 2.3$ & $66 \pm 12$ & $3.3 \pm 0.9$ \\
\hline QT (m/kef/min) & $1606 \pm 50.3$ & $1601 \pm 381$ & $16961 \pm 545$ & $1770 \pm 537$ & $148.1 \pm 470$ \\
\hline $\mathrm{DO},(\mathrm{m} / \mathrm{kg} / \mathrm{mm})$ & $209 \pm 66$ & $184 \pm 49$ & $163 \pm 46$ & $11.0 \pm 30$ & $4.9 \pm 2.2$ \\
\hline $\mathrm{SvO}_{2}^{2}(\%)$ & $564 \pm 117$ & $463 \pm 116$ & $328 \pm 142$ & $11.6 \pm 69$ & $24 \pm 2.9$ \\
\hline $\mathrm{VO}_{2}$ (m) $\left./ \mathrm{kg} / \mathrm{mur}\right)$ & $93 \pm 20$ & $86 \pm 18$ & $90 \pm 2.7$ & $81 \pm 18$ & $42 \pm 1.8^{*}$ \\
\hline FOE & $047 \pm 011$ & $049 \pm 012$ & $058 \pm 016$ & $076 \pm 012$ & $089 \pm 0.10$ \\
\hline Lactare/pyruvate & $127 \pm 32$ & $134 \pm 51$ & $14.0 \pm 3.6$ & $19.4 \pm 86$ & $320 \pm 12^{*}$ \\
\hline$\Delta$ lactate (mmolit) & $01 \pm 04$ & $02 \pm 07$ & $0.5 \pm 13$ & $14 \pm 18$ & $44 \pm 2.4^{*}$ \\
\hline
\end{tabular}

With progressive hypoxemia, $\mathrm{VO}_{2}$ remained unchanged except at the lowest $\mathrm{SaO}_{2}$, because of an increasing $\mathrm{FOE}$ and decreasing $\mathrm{SvO}_{2}$. A significant change in lactate concentration and lactate/pyruvate ratio were only noted when $\mathrm{VO}_{2}$ was decreased. Decreasing $\mathrm{SvO}_{2}$ is an early sign for an increased oxygen extraction to preserve tissue oxygen consumption.

\section{2}

The "PIF" influenced the outcome of patients with acute respiratory distress syndrome and extracorporeal lung support

Höltermann W, van Wickern $M$, Jessen $O$, Lukasewitz P, BittersoblJ, Lennartz $H$

Department of Anesthesiology and Critical Care Medicine, University Hospital, Marburg, Germany

To improve an accurate diagnosis for the application of ELA we evaluated retrospectively the course of disease in 131 patients with ARDS before extracorporeal support was applied. We investigated pulmonary and hemodynamic values such as ventilator support, grading of organ failure, signs of sepsis and management of nutrition. An analysis (Student t-test, Chi square-test) was made on the day before patients were transfered to our ICU. From all variables only the PIF-quotient (PEEP x I:E x FiO ) was different between survivors (11.69 \pm 9.56 ) and non-survivors $(15.48 \pm 10.9)(p<0.05)$. The PIF from KOLLER and BENZER is a quantifying parameter for the strength of the respiratory therapy and defined the severity of illness by a therapeutic procedure. This result shows, 1) the opportunities of conventional ventilation are limited before the maximum of its possibilities are reached; 2 ) whenever firm limits with methods of conventional ventilation are exceeded, the application of extracorporeal support is not useful.
33

A comparison of two parameters reflecting oxygenation during extracorporeal membrane oxygenation

de Boode WP, Geven WB

On behalh of the ECMO Group, Department of Pediatrics, University of Nijmegen, Nijmegen, The Netherlands

Controversy exists about a proper definition of adequate oxygenation. In practice $\mathrm{a} \mathrm{aO}_{2}$ of $10 \mathrm{kPa}(75 \mathrm{~mm} \mathrm{Hg})$ is generally considered as an optimal situation. In many ECMO-centers, as in Nijmegen, the target value of postductal $\mathrm{paO}$, during ECMO is between 10 and $13 \mathrm{kPa}(75-100 \mathrm{~mm} \mathrm{Hg})$. In 1990 Dudell et al concluded the $\mathrm{paO}_{2}$ to be a poor indicator of adequate oxygenation and suggested the mixed venous oxygen saturation $\left(\mathrm{S}_{\mathrm{O}} \mathrm{O}_{2}\right)$ ro be used as such. The relationship between $\mathrm{paO}_{2}$ and $\mathrm{SvO}_{2}$ during several ECMO-runs was analyzed. In 31 neonates on venoarterial ECMO, 2555 concomitant $\mathrm{PaO}_{2}$ and $\mathrm{SvO}_{2}$ values were studied. Adjustment of ECMOflow was based on intermittent postductal $\mathrm{paO}$, measurement by blood gas analysis. $\mathrm{SrO}_{2}$ was assessed "in line" in the ECMO-circuit. We found that when $\mathrm{paO}_{2}$ is $<10 \mathrm{kPa}$, in $32 \%$ of the cases $\mathrm{SvO}_{2}$ is over $55 \%$. This finding confirms the suggestion of Dudell et al that the $\mathrm{paO}_{2}$ is a poor indicator of adequate oxygenation. Considering a $\mathrm{SvO}_{2}$ value between $55-70 \%$ to be a indicator of adequate oxygenation, one could say that in $78 \%$ of the measurements, $\mathrm{SvO}_{2}$ was toohigh and in only $3 \%$ of the cases therewas a state of undersaturation. Possible reasons for the frequent finding of high $\mathrm{SvO}_{2}$ during VA-ECMO are: 1) intracardiac left-to-right shunt due to a reversed pressure gradient over the foramen ovale in the recovery phase (this could not be confirmed by echocardiography); 2) decreased oxygen extraction rate as a result of redistribution of blood flow; 3) reduced oxygen demand due to medical paralysis and sedation. Reviewing these data one might assume that, using the $\mathrm{paO}_{2}$ to determine the pump velocity, the arterial oxygen content is kept unnecessarily high. This might not be without risk, considering the possible formation of oxygen radicals or possible cerebral vasoconstriction due to preferential flow of highly oxygenated blood towards the brain.

34

Thermodilution cardiac output may be incorrect in patients on venovenous extracorporeal membrane oxygenation

Haller M, Zöllner C, Manert W, Briegel J, Kilger E, Polasek J,

Hummel T, Peter $K$

Institute of Anesthesiology, Ludwig-Maximilaans-University of Munich, Munich, Germany

Wetested the hypothesis that if theindicator used todeterminecardiacoutput (CO) is injected into the vena cava or the right atrium, $\mathrm{CO}$ will be overestimated due to indicator loss into the extracorporeal circulation. We compared the results of TD CO measurements with the results of a CO measurement technique which is not affected by the extracorporeal circulation. Seven patients with severe ARDS and treated with ECMO were included in the study. TD CO determinations were carried out using standard equipment. Indocyanine green (ICG) was used for dye dilution (DD) CO measurements. One $\mathrm{ml} \mathrm{of} \mathrm{a} 2.5 \mathrm{mg} / \mathrm{ml}$ ICG solution was used for dye dilution (DD) CO measurements. Blood was withdrawn from an arterial catheter trough a cuvette densitometer connected to a $\mathrm{CO}$ computer. The DD method was assumed to give an accurate cstimatc of $C O$, since no loss of indicator due to ECMO can occur in the pulmonary artery. The TD method was compared to the DD results during ECMO with different blood flows through the extracorporeal circuit. The ratio TD/DD and the difference of TDDD were plotted over ECMO blood flow $\left(\mathrm{F}_{\mathrm{ECMO}}\right)$ in relation to $\mathrm{CO}$ ( $C O$ estimated from $\mathrm{DD})$. We performed weighted least squares regression analysis to account for pooled subject data. Forty-nine data triplets were obtained with $\mathrm{CO}$ ranging from 2.9 to $9.4 \mathrm{~V} / \mathrm{min}$. $\mathrm{F}_{\mathrm{ECMO}}$ ranged from 29 to $106 \%$ of $\mathrm{CO}$. The overestimation of $\mathrm{CO}$ by TD in our experiments was clearly dependent on the fraction of $\mathrm{CO}$ drained through the extracorporeal circuit. Over all, there was a substantial linear increase in overestimation with increasing $\mathrm{F}_{\mathrm{ECMO}} / \mathrm{DD}$. In summary, conventional TD CO determinations are not valid in patients on ECMO. Different approaches such as DD CO measurement with dye injection into the distal port of the PAC are needed to obrain reliable results. 
35

Multiple focal depletion of lactate dehydrogenase in brain after 12 minutes of global ischemia following two hours extracorporeal life support

\section{Mamoru T, Iwao Y, Sakamoto H, Iijima T, Sankawa $H$}

Department of Anesthesiology and Intensive Care Medicine, Kyorin University School of Medicine, Tokyo, Japan

Brain damage following extracorporeal life support (ECLS) is a crucial complication of a resuscitated critically ill patient. Little is known about the mechanism of this complication. Flow disturbance, namely no reflow phenomenon or post-ischemic hypoperfusion, may contribute to the pathophysiology of this complication. To determine how it develops, we applied ECLS to an animal model and examined pathological changes in the brain specimen. Five rabbits were anesthetized with pentobarbital $(20 \mathrm{mg} / \mathrm{kg})$ and mechanically ventilated. Venoarterial extracorporeal circulation (ECC) was connected to the left internal jugular vein and the right internal carotid artery. The ECC system consisted of a membrane oxygenator, a roller pump and a heat exchanger, and was primed with $200 \mathrm{ml}$ of $10 \%$ dextran 40 . Cardiac arrest was induced with $2 \mathrm{M} \mathrm{KCI}$ and $\mathrm{ECC}$ was commenced after 12 minutes of circulatory arrest. ECC was maintained at a flow rate of $40-50 \mathrm{ml} / \mathrm{kg}$. Two hours after ECC, the brain was perfused from the left ventricle with $2 \%$ tetrazolium chloride for vital staining, which is sensitive to flow disturbance and then incubated for 45 minutes. Brains were cut into coronal blocks of 1 $\mathrm{cm}$ thickness for evaluation. After immersed fixation, brain slices were processed forpathological examination with hematoxylene-eosin and KluberBarrera's staining for axon staining. There were multiple patchy depletion of TTC staining in the hippocampus and cerebral cortex and caudate putamen, which suggests flow disturbance during ECC. The left hemisphere was slightly less stained with TTC; however, the less stained areas did not correlate with parhological changes. No reflow and hypoperfusion areas partially agree with selectivevulnerable area of neuron after global ischemia. Slight reduction of lactate dehydrogenase in the cannulated side without pathological change suggests endangered energy supply to the cannulated side of the brain.

\section{6}

Acute renal failure during extracorporeal membrane oxygenation

Midrio P, Gamba PG, Andreetta B, Pettenazzo A, Zanon GF

Pediatric Surgery, Department of Pediatrics, University of Padua,

Padua, Italy

ECMO involves some important complications: bleeding, neurological lesions following brain strokes and bleeding, multiorgan hypoxic insults. We reviewed the charts of the patients treated in the Department of Pediatrics of Padua. Particular attention was given to those which presented with acute renal failure (ARF) during treatment. Since April 1993 we treated eight patients, mean age 22.6 months (range 12 hrs- 8 yrs), affected by acute respiratory failure (5), congenital diaphragmatic hernia (1), multiple pulmonary arteriovenous fistulae (1) and viral myocarditis (1). Mean treatment duration was $142 \mathrm{hrs}$ (range $66-243 \mathrm{hrs}$ ); fourvenoarterial and five venovenous bypasses were performed, including one patient (diaphragmatic hernia) in which the venovenous bypass was switched to venoarterial due to inadequate drainage. Two patients died (25\%). Complications were fatal brain bleeding, progressive neurological damage and in one patient $(23 \mathrm{mo}, 16 \mathrm{~kg}$, viral myocarditis) cerebral stroke, hemothorax, hemopericardium and acute renal failure. This one, begun after five hours of ECMO, was treated with continuousarterial-venousdiahemofiltration (CAVH-D), urilizingan ECMO circuit. Initial fow rate of the circuir was $600 \mathrm{ml} / \mathrm{min}$; when ARF began it was $1200 \mathrm{ml} / \mathrm{min}$ and the patient's blood pressure $79 / 60 \mathrm{~mm} \mathrm{Hg}$. Total ECMO treatment duration was 118 hrs; CAVH-D lasted 200 hrs. Peritoneal dialysis was started on the ninth day of ARF as CAVH-D was malfunctioning. The patient recovered normal renal function after 30 days from the onset of $A R F$. The rare of ARF during ECMO is not well established; some authors report up to $30 \%$ incidence in cardiac patients. In our experience it occurred in $12.5 \%$ ( 1 patient), which corresponds to the percentage reported by the USA ECMORegistry. This complication is easily handled with the hemofil tration or CAVH-D technique, which utilize the venovenous or venoarterial accesses already arranged. Peritoneal dialysiscan be used ifARF does not resolveduring ECMO treatment.
37

Continuous hemodialysis during AREC for capillary leak syndrome and acute renal failure

Renolleau S, Chevalier JY, Deschenes $G$

Hopital Trousseau, Paris, France

A 10-year-old girl (weight $40 \mathrm{~kg}$ ) who was admitted in our unit for a systemic inflammatory response syndrome, developed rapidly an acute respiratory distress syndrome. Two days after admission, shemet AREC criteria $\left(\mathrm{AaDO}_{2}\right.$ $614, \mathrm{OI} 65)$. During this AREC we added to the usual circuit a continuous femoral drainage connected to the drainage line after the clampwhich raied the flow by $30 \%(750 \mathrm{ml} / \mathrm{min})$. Despite inotropic drugs and oxygenation improvement during AREC, the patient developed acute renal failure and capillary leak syndrome. Continuous venovenous hemodiafiltration was begun two days after the onset of AREC (Gambro ${ }^{\oplus} \mathrm{HF} 60$ ). However, she showedhigh serum urea and creatininelevels and it was impossible to decrease fluid overload because of poor hernodynamic status. Thus we performed a continuous venovenous hemodialysis (CVVHD) during 24 hours with cellulose acetate membranes (Baxter ${ }^{18} \mathrm{CA} 130$, area $1.3 \mathrm{~m}^{2}$ ). The CVVHD circuit was connected in parallel to the femoral drainage line. The CVVHD flow was $250 \mathrm{ml} / \mathrm{min}$. Atthebeginning ofCVVHD urea, creatinineand protidemialevels were respectively $40.5 \mathrm{mmol} / \mathrm{L}, 470 \mu \mathrm{mol} / \mathrm{Land} 45 \mathrm{~g} /$. Arterial pressure was $81 /$ $38 \mathrm{~mm} \mathrm{Hg}$. During the following 24 hours, the net ultrafiltration rate was increased from 110 to $1400 \mathrm{ml} / \mathrm{h}$. At the end ofCVVHD the urea, creatinine and protidemia levels were $2.5 \mathrm{mmol} / 1,44 \mu \mathrm{mol} / /$ and $65 \mathrm{~g} / \mathrm{l}$. The total fluid removal was 11 liters. Moreover, during CVVHD, as the fluid overload was decreasing, arterial blood pressure was increasing to reach the normal value. AREC was discontinued after 209 hours because of lung recovery. Conventional hemodialysis was still performed daily for 9 days and then every two days. Hemodynamic status became normal and capillary leak syndrome disappeared. Unfortunately the girl died at day 33 because of gram negative sepsis. This case suggests that CVVHD is a good alternative to continuous hemodiafiltration as a treatment for acute renal failure and capillary leak syndrome in parients whodo not respond well to continuous hemodiafiltration.

38

A miniaturized circuit and oxygenator for venovenous extracorporeal lung support (AREC) in New Zealand rabbits

Petion AM, Chevalier JY, Renolleau $S$

PICU Children's Hospital, Dijon and PICU Armand-Trousseau Children's Hospital, Paris, France

We have tested a new silicone membrane diffusion oxygenator (Jostra ${ }^{\circledR}$ M5, Germany) in 10 New Zealand rabbits (mean weight $2980 \pm 195 \mathrm{gm}$ ) treated by VV-ECLS (AREC). The M5 oxygenator is solid with metal exchange plates and aluminium housing coated with silicone. The surface area is $0.4 \mathrm{~m}^{2}$ with a priming volume of $30 \mathrm{ml}$, allowing a maximal blood flow of $0.51 / \mathrm{min}$. We used a $8 \mathrm{Fr}$ cannula. The tubing was $3 / 16$ inches ID (priming $80 \mathrm{ml}$ ). The pump was non-occlusive with an elliptic silicon tubing in the head pump (priming $50 \mathrm{ml}$ ). The heat exchange was provided by a water circuit surrounding the tubing and the oxygenator. The total circuit was primed with $150 \mathrm{ml}$ of the blood of a rabbit donor. The natural lungs were ventilated with apneic oxygenation alone or associated with low frequency positive pressure ventilation. The mean $\mathrm{paO}_{2}$ was $148.2 \pm 57.7 \mathrm{~mm} \mathrm{Hg}$; the mean $\mathrm{paCO}_{2}$ was $29.4 \pm 5.8 \mathrm{~mm} \mathrm{Hg}$; and the $\mathrm{SaO}_{2}$ was $95.6 \pm 7.9 \%$, with a mean blood flow of $131 \pm 43.2 \mathrm{ml} / \mathrm{min}$ and a gas $/$ blood flow ratio of $4: 1\left(\mathrm{FiO}_{2} 0.4\right)$. The outlet/inlet blood gases were $163 \pm 56.1 / 44.6 \pm 5.6 \mathrm{~mm} \mathrm{Hg}$ for $\mathrm{pO}_{2}$; 17.8 $\pm 4.7 / 29.3 \pm 4.3 \mathrm{~mm} \mathrm{Hg}$ for $\mathrm{pCO}_{2}$ and $98.9 \pm 3.3 / 72.7 \pm 6.5 \%$ for oxygen saturation. During apneic oxygenation alone, the oxygenator $\mathrm{CO}_{2}$ transfer was $14.3 \pm 2.00 \mathrm{ml} / \mathrm{min}$ and the $\mathrm{O}_{2}$ transfer was $5.4 \pm 0.6$ with a mean blood flow rate of $182 \pm 11 \mathrm{ml} / \mathrm{min}$ and a gas flow of $1.42 \pm 0.121 / \mathrm{min}\left(\mathrm{FiO}_{2} 0.54\right)$. This membrane has a low resistance with a pressure drop of $11 \pm 4 \mathrm{~mm} \mathrm{Hg}$. We conclude that this new miniaturized AREC could be used for partial extracorporeal support in neonates. 
39

Comparison of the effect of a membrane and a hollowfiber oxygenator on platelet function- in vitro studies

Mellgren K, Friberg LG, Wadenvik $H$, Mellgren $G$

Department of Pediatric Surgery, East Hospital and Department of

Medicine, Sahlgrens Hospital, University of Göteborg, Göteborg, Sweden

Two complete ECMO circuits were primed with fresh, heparinized human blood and circulated for 24 hours. Two sets of experiments were performed, one with a true membrane lung (SciMed, Minneapolis, USA) and another with a holofiber lung ("Lilliput," Dideco, Italy). Blood gases, electrolytes, glucose and hematocrit were kept within physiological ranges. Release of betathromboglobulin, serotonin and glycocalicin were assayed, and platelet membrane density of glycoproteins (GP) were studied using monoclonal antibodies and flow cytometry. The platelets in the membrane circuits were cleared from the circulation at a higher rate than for the hollowfiber group. The difference in platelet count was statistically significant at the 0.5 and 1 hour measurements. Furthermore, remaining platelets in the membrane group had a reduced surface expression of GPIb as compared to the hollowfiber group where platelet membrane density of glucoproteins were unchanged throughout the 24-hour experiment.
40

Quality improvement with a neonatal extracorporeal membrane oxygenation care-map in the pediatric intensive care unit

King $R$

Duke University Medical Center, Durham, USA

Extracorporeal membrane oxygenation (ECMO) is successful in neonatal patients when conventional therapies have been ineffective. The care of a patient receiving ECMO requires the combination of sophisticated intensive care technologies with the collaboration of an extensive multidisciplinary team. In order to effectively utilize limited health care resources, a care-map for neonatal patients receiving ECMO was developed. The care-map outlines a critical path that guides the patient's care and identifies patient and family problems using nursing diagnoses. The critical path describes the specific care requirements in relation to multidisciplinary consults, laboratory and diagnostic tests, nursing treatments, medications, diet activity, family education and discharge planning. The first year of continuous variance monitoring has resulted in the elimination of unnecessary laboratory tests, revision of medications, and a decrease in the frequency of diagnostic treatments. Utilizing the care-map has improved co-ordination of care and decreased costs incurred by the family and hospital. This poster will present the ECMO care-map, strategies for implementation, and the quality improvement data demonstrating the clinical and financial benefits of care mapping in critical care.
41

Use of the ELSO Registry to document the safety and efficacy of extracorporeal life support equipment

Bartlett RH, Hirschl RB

The University of Michigan Medical Center, Ann Arbor, USA

Every country has some regulatory agency which oversees the safery of medical devices. In the United States this is the FDA. To qualify a device for sale, and to document the continued safety of the device, any company must provide safery and efficacy data which meets FDA requirements. In a small but complex field like ECLS, specific testing guidelines are vague, data accumulation is difficult and expensive, and the final potential market is small. Therefore, the process of regulation, however necessary, inhibits device development and patient care. Many of these problems can be solved by using the ELSO Registry data to evaluate safery and efficacy of devices. With 10,000 cases in the Registry, and with the incidence of device failure documented, it is possible to collect a very large amount of data both retrospectively and prospectively which could not be done as well in a multi-center prospective study. Representatives from FDA and the ELSO Devices Committee have worked together toward developing standard testing and reporting guidelines for ECLS devices, using Registry data to quantitate safety and efficacy for re-labeling of existing devices and evaluation of new devices. The pilot trial of this joint approach to satisfying regulations is being conducted by Cobe Laboratories, ELSO Devices Committee, and FDA Cardiovascular Devices Branch. In this pilot, thousands of ECLS patients managed with the Cobe roller pump will be evaluated for the incidence of pump failure (approximately $2 \%$ ) and the effect of pump failure on ultimate survival (no effect). With this approach device companies, regulatory agencies, and physicians can evaluate and document device performance at minimal cost to the mutual benefit of our patients.

42

Severe adult respiratory failure-results of a standardized management protocol

Pranikoff T, Hirschl RB, Fazzalari FL, Bartlett RH

University of Michigan, Ann Arbor, USA

In 1990, we instituted a management protocol for adult respiratory failure (ARF) which includes: 1) optimizung oxygen delivery in relation to $\mathrm{VO}_{2}$ (cardiac output, $\mathrm{Hgb}$, mean and expratory airway pressure) based on $\mathrm{SvO}_{2}$ and $\mathrm{SaO}_{2}$;2) diuresis to dry weight; 3) prone positioning; 4) $\mathrm{FiO}_{2}$ limited to 0.6 maximum., accepting hypoxemia if necessary; 5) pressure controlled ventilation limited to $40 \mathrm{~cm} \mathrm{H}_{2} \mathrm{O}$ PIP maximum, accepting hypercarbia if necessary; and 6) extracorporeal life support (ECLS) if adequate gas exchange and systemic perfusion could not be achieved using these measures. This protocol was evaluated in patients $18-60$ years old on mechanical ventilation less than two weeks, with $\mathrm{paO} / \mathrm{FiO}$ less than 75 . This defines a patient group with mortality risk $60-90 \%$ with computer-directed (Morris) or other conventional care (Suchyta, Simmons, Zapol). One hundred patients were managed on this protocol; 65 survived (65\%). Seventy-two were referred for ARF management; 28 originated in our ICU. All werc $\mathrm{FiO}_{2} 1.0, \mathrm{paO}_{2}<75$, Qsp/Q $\triangleright 40 \%$ at the time of referral.Average agewas 34 years. Diagnoseswere bacterial pneumonia in 21 patients (10 survived), viral pneumonia in 17 patients (12 survived), ARDS in 56 patients ( 37 survived), airway obstruction in 4 patients (all survived), and pulmonary embolism in 2 patients (both survived). Thirty-three improved without ECLS; 6 of these died later of other causes. Sixty-seven required ECLS ( 46 acurely and 21 after at least 12 hours of protocol management). Thirty-eight of these ECLS patients survived (57\%); 15 ECLS patients died of progressive pulmonary fibrosis and 14 died of other causes. There was a significant correlation between ventilator days before the protocol was begun and fatal pulmonary fibrosis. The only longterm disability is deafness in two parients. These results compare favorably to other management protocols recorded in the literature. A management protocol emphasizing optimal $\mathrm{DO}_{2}$, low pressure, low $\mathrm{FiO}_{2}$ ventilation, and lung rest with ECLS resulted in $65 \%$ survival in severe ARF. 
43

Surgical interventions during the treatment of severe adult respiratory distress syndrome-a five-year experience Lüsebrink R, Lemmens HP, Weidemann H, Pappert D, Rossaint $R$, Falke KJ, Neuhaus $P$

Departments of Surgery and Anesthesiology and Intensive Care, Klinikum Rudolf Virchow, Berlin, Germany

Severe damage of lung parenchyma leading to adult respiratory distress syndrome (ARDS) may require treatment with conventional therapeutic means like dehydration, pressure-controlled ventilation and posture maneuvers. When improvement of gas exchange remains unsatisfactory extended therapy by application of extracorporeal membrane oxygenation (ECMO) may be considered. This makes transportation of the respective patients to the operation theatre almost impossible and requires surgical procedures to be performed at the ICU-bed. Due to favorable experiences with surgical procedures performed in the ICU when this was inevitable, we increasingly performed all surgery for ARDS patients at their ICU-beds, thus reducing the hazards of transportation and translocation for these critically ill patients. We report our experience with 218 operative interventions in 97 consecutive patients treated for severe ARDS on the anesthesiological ICU between April 1989-April 1994. Only $14.9 \%$ of operations were performed in the operation theatre. The majority of operations $(72 \%)$ had to be performed on an emergency basis-mainly thoracotomies for pneumoand/or hemathoraces. Only tracheotomies and decannulations were elective procedures (24\%), while repositioning of cannulas was regarded as semi-elective $(4 \%)$. Patients who recovered under conventional therapy had less surgical interventions ( 1.04 per patient) and a better survival rate $(88 \%)$ when compared to patients who required extended therapy by the use of ECMO. Their survival rate was $54 \%$ and they required an average of 3.9 surgical interventions per patient. Close cooperation between anesthesiologists and surgeons seems mandatory for successful treatment of severe ARDS.

44

Major surgical procedures during extracorporeal respiratory support with heparinized circuits

Marcolin R, Bombino M, Manetti B, Fumagalli R, Giuffrida A, Maisano P, Benenti C, Gramazio P, Pesenti A

Department of Anesthesia and Intensive Care, S. Gerardo Hospital, Monza, Italy

Bleeding is the major side effect of extracorporeal respiratory support (ERS), and often a surgical procedure is required for hemostasis. In anticoagulated patients however major surgical procedures may be potentially life-threatening by causing further bleeding. Since 1989 we applied percutaneous venovenous ERS in 40 patients with severe respiratory failure, 10 of whom underwent surgical maneuvers. In seven of these 10 patients, we used surface heparinized circuits (Carmeda, Medtronics), complemented by 16000-20000 UI of heparin per day by constant IV infusion. A few hours before surgery, the heparin IV infusion was temporarily discontinued. We performed 3 thoracotomies to control major chest bleeding ( $>300 \mathrm{ml} / \mathrm{hr}$ ) and a pericardiectomy following three episodes of cardiac tamponade. Four laparotomies were performed in three other patients for gastric hemorrhage, hemoperitoneum, ileus and bladder bleeding. Three of the seven patients finally survived (43\%). The survivors had only one organ failure beside the lung. Three of the non-survivors had more than three organ failures. The use of heparinized circuits allowed us to perform major surgical procedures with normal or close to normal coagulation status while on bypass.
45

Long-term respiratory assistance with heparinized circuits Bombino M, Borelli M, Marcora B, Rossi GP, D'Andrea L, Gattinont $L$, PesentiA

Department of Anesthesia and Intensive Care, S. Gerardo Hospital, Monza, Italy

Since 1986 surface heparinized circuits have been introduced in clinical practice to reduce the risk of bleeding related to full anticoagulation. We started to use heparinized surface devices routinely for extracorporeal respiratory assistance in 1992. Since then we have treated 17 ARDS patients (mean age 27.8 \pm 20.3 years, range $2-55$ ); 7 of them survived. Mean intubation time before bypass was $12 \pm 9$ days.

$$
\begin{array}{cccccc}
\mathrm{paO}_{2} / \mathrm{FiO}_{2} & \mathrm{Qva} / \mathrm{Q} & \mathrm{PEEP} & \mathrm{PaCO}_{2} & \mathrm{VE} & \mathrm{mPAP} \\
\mathrm{mm} \mathrm{Hg} & \mathrm{percent} & \mathrm{cm} \mathrm{H_{2 } \mathrm { O }} & \mathbf{m m ~ H g} & 1 / \mathrm{mn} & \mathrm{mm} \mathrm{Hg} \\
686 \pm 364 & 48 \pm 11 & 12.5 \pm 2.7 & 668 \pm 21.7 & 10.2 \pm 3.6 & 34.5 \pm 8
\end{array}
$$

Venovenous bypass ( 15 cases femoro-femoral, 2 cases femoro-jugular) was established by percutaneous insertion of heparinized catheters (Biomedicus). Patients were slightly anticoagulated (PTT 45-55 seconds) with a continuous infusion of heparin while on bypass. Heparin was discontinued only if bleeding was a problem or if there was the need of a surgical procedure. The average bypass lasted $26 \pm 18$ days (range 257 days) for a total of 446 days. Ten patients were supported on bypass for three weeks or more; 6 of them survived. The total number of artificial lungs (Carmeda, Medtronics) used was 44; they lasted 9.5 \pm 5.8 days on average. Changes were prompted by a decrease in performance and/or activation of coagulation. We used centrifugal pumps (Biomedicus) and the pump heads were changed whenever overt hemolysis was detected. The total number of pump heads used was 65 with a mean length of $6.9 \pm 3.3$ days. Heparinized artificial lungs showed a good long-term performance. A careful monitoring of coagulation parameters and hemolysis is mandatory with the use of centrifugal pumps.

46

Transport venoarterial extracorporeal membrane oxygenation of a newborn with total anomalous pulmonary venous drainage as a bridge to surgical repair-a case report

Zábrodsky V, Stranák Z, Kucera V, Getlik P, SimákJ

Institute for the Care of Mother and Child, Department of

Cardiosurgery, University Hospital Motol and Emergency Ambulance Service, Prague, Czech Republic

A full-term newborn presented on the 8th day after birth with a systolic murmur and tachycardia. During the next 2 days, the patient demonstrated progressive deterioration. On day 10 , the patient was admitted to our NICU with acure respiratory failure due to suspected fulminant bronchopneumonia. Regional cardiology evaluation excluded congenital heart disease. After admission we found signs of pulmonary hypertension (right-to-left shunt at PDA and FOA), systemic hypotension and hypoxemia. We started IPPV (Babylog8000, Dräger) and inhalation of 15 ppmof nitricoxide (Pulmonox ${ }^{\circledR}$, Messer-Griesheim) leading to an intermittent improvement. Two-dimensional ultrasonography examination led us to thesuspicion of TAPVD, which was consequently confirmed (obstructed, infradiaphragmatic). Because of dramatic deterioration $\left(\mathrm{AaDO}_{2}>600 \mathrm{~mm} \mathrm{Hg}, \mathrm{OI}>40, \mathrm{paO}_{2} 30 \mathrm{~mm} \mathrm{Hg}\right)$ during a few hours, we had to start venoarterial ECMO. We used the system Biomedicus (centrifugal pump BP 50 and Avecor oxygenator) incorporated together with a heater (Cincinnati Sub-Zero) in a Babytherm transportable bed (Dräger). The patient was stabilized on ECMO (flow $150 \mathrm{ml} / \mathrm{min}$ ) and transported in the "honeymoon" condition in an ambulance to the Department of Cardiosurgery. Surgical repair was performed on conventional cardiopulmonary bypass (Dideco) and after the operation the ECMO was continued. Thirty hours after theoperation the patient could be weaned from ECMO. Unfortunately, the patient died 16 hours after the weaning due to heart failure. Despite generally accepted contraindication of ECMO therapy in congenital heart diseases, we believe, that in some cases with a good surgical prognosis, the transport-ECMO might serve as a bridge to surgical repair and thus prevent irreversible hypoxic injury. 
47

Extracorporeal membrane oxygenation for transport of hypoxemic patients with severe acute respiratory distress syndrome

Rossaint R, Gerlach H, Pappert D, Lewandowski K, Falke KJ Klinik fur Anaesthesiologie und Operative Intensivmedizin, UKRV, Freie Universitat Berlin, Berlin, Germany

The interhospital transfer of hypoxemic patients $\left(\mathrm{paO}_{2} / \mathrm{FiO}_{2}<50 \mathrm{~mm} \mathrm{Hg}\right)$ is associated with the danger of cerebral hypoxia and death. Therefore, we initiated ECMO in this group of patients before the interhospital transfer. From June 1993 to December 1994, eight patients with a $\mathrm{paO}_{2} / \mathrm{FiO}_{2}<50$ $\mathrm{mm} \mathrm{Hgat} P E E P \geq 10 \mathrm{~cm} \mathrm{H}_{2} \mathrm{O}$ for $>2 \mathrm{~h}$ were referred for treatment of ARDS Since one of the eight patients was immunosuppressed and another one died within two hours after the first phone call, six patients remained to be transferred to our ICU. In four cases, an air transport system and in two cases an ambulance were chosen. For the interhospital transfer a mobile intensive care unit, a bus, was used. This bus is equipped with a blood gas, hemoglobin and electrolyte analyzer, with one mobile and one immobile monitor system, including ECG, direct arterial and pulmonary artery pressure as well as pulse oximetry, infusion pumps and a bed ouffitted with a Siemens 300 ventilator and an independent power and gas supply. The transport team consisted of two anesthesiologists and one nurse all experienced with ECMO technique. If after arrival in the referring hospital, the patients' $\mathrm{paO}_{2} / \mathrm{FiO}_{2}$ was still below $50 \mathrm{~mm} \mathrm{Hg}$ at $P E E P \geq 10 \mathrm{~cm} \mathrm{H}_{2} \mathrm{O}$, venovenous ECMO was initiated in the patient's bed. In all six patients this procedure could besuccessfully performed. ECMO could be started $8 \pm 2.4 \mathrm{~h}$ after the request to transfer a patient; the interhospital transfer lasted $5.4+2.7 \mathrm{~h}$. Comparing gas exchange parameters and ventilatorsettingsbefore transfer without ECMO with those after transfer with $\mathrm{ECMO}$ demonstrated that $\mathrm{paO}_{2}$ increased by $21 \pm 7 \mathrm{~mm} \mathrm{Hg}(\mathrm{p}=0.001)$, $\mathrm{paCO}_{2}$ decreased by $16 \pm 10 \mathrm{~mm} \mathrm{Hg}(\mathrm{p}=0.02), \mathrm{FiO}_{2}$ by $0.22+0.17(\mathrm{p}=0.03)$, peak inspiratory pressure by $10 \pm 5 \mathrm{~cm} \mathrm{H}_{2} \mathrm{O}(\mathrm{p}=0.003)$, and respiratory rate by $14 \pm 5.6$ beats $/ \mathrm{min}(\mathrm{p}=0.002)$. Two patients died due to multipleorgan failure. Initiation of ECMO in hypoxemic patients before interhospital transfer is possible and may be advantageous.

48

Transport of unstable patients on extracorporeal life support

Shapiro M, Anderson H, Pranikoff T, Chapman R, Bartlett $R$ University of Michigan, Ann Arbor, USA

As ECLS technology is expanded to children and adults with cardiorespiratory failure, the absence of well-established regionalization and intercenter referral has become a significant problem. Older patients do not tolerate transportation as well as neonates. We developed a transport system to facilitate safe movement of these patients to our hospital. If conventional transport was believed impossible due to severity of illness, the ECLS team went to the referring hospital by ground or air transit. This team included two ECLS physicians, two ECLS technical specialists, one flight nurse, and one ambulance driver. Cannulation was performed with the assistance of the referring hospital's operating room team, ECLS initiated, and the patient stabilized. A specially designed ECLS cart for transport was used, and the patient and team were moved by ground ambulance to the University of Michigan Hospital. We have utilized ECLS in the management of 51 cases of severe adult respiratory failure with an overall survival of $57 \%$. Fourteen of these patients were too unstable to be safely transported using conventional ventilation and were placed on bypass at the referring institution. Diagnoses in thisgroupindudedARDS (8), pneumonia (5), andasthma(1).Venoarterial access was used for 12 patients, venovenous access for 2 . Pre-ECLS ventilator support was $\mathrm{FiO}_{2} 0.98 \pm 0.07$, rate 19 \pm 5 , PIP $57 \pm 12$, PEEP 14 1 . Physiologic indicators of severity of respiratory failure induded $\mathrm{SaO}, 84 \pm 11, \mathrm{pO}, 67 \pm 43$,

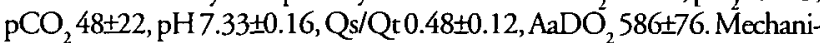
cal complications during transport included generator failure (2) and arterial line disconnection (1); however, there were no adverse effects on patient outcome. Average distance transported was 78 miles; the averageduration was 8 hours. Total time on bypass was $223 \pm 201$ hours. Twelve of the 14 patients (86\%) survived to discharge. Transport with ECLS is labor intensive, but can be done safely, and represents an important option for patients too ill to move with conventional support.
49

Intrahospital transport of adult patients on extracorporeal lung assist Borg UR, Cunsolo LA, Reynolds HN, Habashi NM

R. A. Cowley Shock Trauma Center, Department of Critical Care Medicine, Baltimore, USA

Patients supported by ECLA frequently require surgery or diagnostic studies. Traveling with an ECLA patient has been considered impossible due to the complex and bulky equipment-i.e. ECLA equipment, ventilator with power source, patient monitor and infusion pumps. Another limiting factor is the inability to maintain ECLA blood flow while traveling, due to increased siphon pressure as a result of lower bed height during travel. We have developed a method to move ECLA patients to any diagnostic or surgical suite without interruption of ECLA support. The ECLA perfusion system has a self-contained powerpack allowing 45-60 minutes of battery operation. A vertically adjustable gurney is used to maintain patient elevation. Patient lung volume is preserved by utilizing continuous positive airway pressure (CPAP). The CPAP system consists of a flowmeter for gas delivery, 1 liter reservoir bag, patient tubing, adjustable PEEP valve and airway pressure monitor with alarms for high and low pressure. The patient is placed on CPAP equal to the mean airway pressure while on the ventilator and blood gases are obtained after 20 minutes. If blood gases are satisfactory $\left(\mathrm{SaO}_{2}>90 \%, \mathrm{pH}>7.25\right)$, the patient is transferred by "scoop stretcher" to the travel gurney. Immediately prior to departure from the ICU, both CPAP and oxygenator sweep gas are transferred to portable $\mathrm{O}_{2}$ cylinders. The ECLA perfusion system is switched to battery operation. In one year, 8 patients were transported for 10 diagnostic studies and 3 major surgical procedures. There were no medical or technical complications durnng transport. Since carbon dioxide removal is accomplished by the ECL.A system, ventulation is not necessary. Thus, a bulky transport ventilator is unnecessary and a very small CPAP system is adequate for oxygenation.

50

Capgras' syndrome-a complication of venoarterial extracorporeal membrane oxygenation for hypoxemia with multiple organ failure and septic shock

Dejode JM, Antonint F, Ptllon P, Lagier P, Soula F, Vialet R, Alimi Y, Habib M, Martin C

Department of Anesthesia and Intensive Care, Centre HospitaloUniversitaire Nord, Marseilles, France

Watershed cerebral infarcts are very rare ischemic lesions. We describe a 24-year-old woman who survived this insult after border zone infarction distal to primitive carotid artery occlusion following venoarterial extracorporeal membrane oxygenation (VA-ECMO). VA-ECMO was established for severe hypoxemia (arterial oxygen saturation 65\%) with multiple organ failure (heart, kidney and liver) and for barotrauma (bilateral pneumothorax, pneumomediastinum, pneumoperitoneum) under mechanical ventilation (positive end-expiratory pressure $20 \mathrm{~cm}$ $\mathrm{H}_{2} \mathrm{O}$, mean airway pressure $40 \mathrm{~cm} \mathrm{H}_{2} \mathrm{O}$ ) during septic shock duc to Streptococcus pneumonia. Blood was collected in the right atrium and reinjected in the right primitive carutid artery after ligature of the distal segment. After 10 days, vital funcrions and blood gases were improved and VA-ECMO was withdrawn. A reconstruction of the carotid artery was performed with endogenous saphenous vein prosthesis. During withdrawal of sedation, the patient presented seizure disorders with myoclonic movements of the right lower limb. The clinic examination found visual hallucinations with optical illusion and permanent distortion of objects (Capgras' syndrome). An electroencephalogram showed periodic lateralized epileptiform discharges on the posterior right hemisphere. CT-scan showed a watershed cerebral infarct between the right middle cerebral artery and the right posterior cerebral artery. Under anticonvulsant therapy, clinic and electric disorders disappeared. This border zone ischemia is reported as a possible complication after prolonged carotid occlusion. This emphasizes the risk of blood reinjection in the primitive carotid artery during VA-ECMO. 


\section{1}

Acute respiratory failure in severe pancreatitis-influence of ECMO treatment on monocyte HLA-DR expression-preliminary report Quintel M, Richter A, Nebe TH, Tillmanns R, Schwall G, Roth $H$, Meinhardt J

Departments of Anesthesiology and Intensive Care, Surgery, Clinical Chemistry, Klinikum Mannheim, Faculty of Clinical Medicine, University of Heidelberg, Mannheim, Germany

Monocyte HLA-DR expression has been shown to be a good marker for individual immune response. Low HLA-DR levels over more than five days are correlated with lethal outcome in transplant and septic patients. In our own study we could demonstrate the same predicting reliability of suppressed HLA-DRexpression in patientswith severe necrotizing pancreatitis. DePalma observed an increase in lymphocyte HLA-DR expression beginning one day after starting extracorporeal lung support (ECMO) for neonatal respiratory failure. We report a case of severe respiratory failure caused by necrotising pancrearitis in 36-year-old female patient. Progressing respiratory failure was the reason for ICU admission. Despite an $\mathrm{FiO}_{2}$ of 1.0 and a PEEP level of 8 mbar, $\mathrm{paO}_{2}$ levels remained below $60 \mathrm{~mm} \mathrm{Hg}$. We started with advanced treatment of acutelung injury including pressure-limited pressure-controlled ventilation, increasing PEEP levels up to $14 \mathrm{mbar}$, negative fluid balance and prone position fo 24 hours. Despite these maneuvers, $\mathrm{paO}_{2}$ levels still remained hypoxic. After 24 hours of advanced treatment, ECMO therapy was started. The patient stayed on bypass for 160 hours and was weaned off successfully; 36 hours after bypass therapy she was extubared. From the day of hospitalization she was monitored for HLA-DR antigen expression and C reactive protein (CRP) values (cytoluorometric analysis and antigen-antibody reaction). Starting with very low HLA-DR values, levels increased daily, and at the same time CRP levels started to decrease.This development was correlated with a distinct clinical improvement. In conclusion, improvement of monocyte function correlated with the onset of bypass therapy. Further studies will have to show if this potential side effect leads to an effective stimulation of monocyte HLA-DR expression with benefical effects.

\section{2}

Extracorporeal lung and heart assist as a bridge to double-lung transplantation

Noreng M, Steinbruchel D, Lindskov C, Hjortsholm K, Bellaiche L, Poulsen P, Jakobsen CJ, Pettersson $G$

Department of Cardiothoracic Anesthesia and Cardiac Surgery, Skejby Hospital Aarhus, Rigshospitalet, Copenhagen, Denmark

A 16-year-old boy with a tentative diagnosis of primary pulmonary hypertension was admitted to the hospital to exclude pulmonary parenchymal disease. A lung biopsy was done by thoracoscopic procedure. Postoperatively he was hypotensive, tachycardic, with low $\mathrm{SaO}_{2}$ and high pulmonary pressures. We then decided to treat the patient with venoarterial ECMO-heparin-coated tubes (Carmeda), membrane oxygenator (Maxima) and centrifugal pump (Biomedicus). When he was stabilized, we tried to end ECMO by help of inotropes and vasodilators. We also used prostacyclin and $\mathrm{NO}$, without result. Then the patient was ready for lung transplantation, and after 6 uncomplicated days on ECMO, he was double-lung transplanted. The switch from ECMO to ECC was without problems. Postoperatively, he had bleeding problems and the patient died of funginal sepsis after 9 days. Our conclusion is that venoarterial ECMO was a useful mechanical circulatory support in this patient.
53

Postcardiotomy recovery after repair of congenital defects - comparison of extracorporeal membrane oxygenation with ventricular assist device

Glauber M, Gamba A, Mamprin F, Crupi G, Annecchino P, Senni M, Terzi A, Somaschini M, Ferrazzi P

Departments of Cardiac Surgery and Neonatology, Ospedali Riuniti, Bergamo, Italy

From June 1988 to December 1994,23ptswere placed on assisted circulation for acute postcardiotomy shock after repair of various congenital heart defects. Twenty-three pts, ages $2.9 \pm 3.3$ yrs and weighing $12.6 \pm 9.1 \mathrm{~kg}$, were mechanically supported for a mean period of $4.5 \pm 2.4$ days. ECMO was used in $13 \mathrm{pts}$ and VAD in 10 ( 6 left and 4 biventricular assist devices). A Biomedicus $50 \mathrm{~m}$ head pump and a Scimed $0.8-15 \mathrm{~m}^{2}$ oxygenator (in the ECMOgroup) were used in each case. The diagnoses were TOF (10), AVSD (4), VSD (3), TGA (2), PA (1), Ebstein (1), AS (1) and complex malformation (1). Mechanical support (MS) was initiated in ICU in 13 pts after a mean time from cardiopulmonary bypass (CPB) of $14.5 \pm 17.4$ hours. The remaining $10 \mathrm{pts}$ were unweanable from $\mathrm{CPB}$ and received MS in the operaring room. Fifteen (65\%) pts were weaned from MS; 11 (47\%) were discharged and are longterm survivors. The most frequent complications were bleeding (12), chest reopening for tamponade (8), infection (G), renal failure (12), thromboembolism (3). The cause of deach during MS was brain damage (3), untreatable bronchial bleeding (2), sepsis (2), multi-organ failure (5). Two deaths occurred respectively 23 and 20 days after MS removal. There was no significant difference between pts with ECMO and VAD in terms of gender, age, weight, duration of MS, time from $\mathrm{CPB}$ and complication rate. In contrast, a significant difference was observed in the amount of blood loss and outcome of pts. ECMO pts had a blood loss of $295 \pm 275 \mathrm{ml} / \mathrm{kg}$ compared to a blood loss of $65 \pm 72 \mathrm{ml} / \mathrm{kg}$ in VAD pts $(\mathrm{p}<0.01)$. Four pts on ECMO were weaned and 3 survived, while 9 pts were weaned $(p<0.02)$ and 8 survived in the VAD group $(\mathrm{p}<0.006)$. We believe that the use of either left ventricular or biventricular assisted circulation is the mechanical support of choice in pts with acute postcardiotomy shock after repair of congenital heart defects.

\section{4}

Extracorporeal membrane oxygenation as bridging to cardiac transplantation after pediatric cardiac surgery

Alexi-Meskishuli V, Potapov E, Weng Y, Lange P, Hetzer $R$

German Heart Institute Berlin, Berlin, Germany

From September 1991 to September 1994, 1150 pediatric parients underwent surgery involving extracorporeal circulation at the German Heart Institure Berlin. Twenty-six of these (2.26\%), aged 10 days to 13 years old, subsequently were placed on extracorporeal membrane oxygenation (ECMO), six of whom were awaiting cardiac transplantation $(\mathrm{HTx})$ and one heart-lung transplantation (27\%) due to persistent myocardial insufficiency. ECMO was used on six patients to treat low cardiac output syndrome due to hemodynamically associated deficits after a complex operation and on one to stabilize his condition after right ventricular myocardial failure. Six of these seven patients were connected to ECMO immediately after surgery and the other after a twohour stay in intensive care. ECMO duration varied from 50-401 hours. Major problems during ECMO therapy were heavy bleeding and mechanical complications. HTx was later performed on 3 of the 7 patients (43\%); two were later discharged, the third died due to acute rejection. Our experience indicates that, contraindications notwithstanding, ECMO can be used as a life-saving bridge to HTx in cases of severe cardiopulmonary insufficiency caused by hemodynamically associated deficits after complex operations. 
55

The role of transesophageal echocardiography in children on extracorporeal life support

Kececioglu D, Galal O, Gehrmann J, Halees Z, Fadely F, Wilson $N$, KotthoffS, Vogt J

Department of Pediatric Cardiology, Westfalische Wilhelms Universität, Münter, Germany and the Department of Cardiovascular Diseases, King Faisal Specialist Hospital and Research Center, Riyadh, Saudi Arabia

To determine the value of transesophageal echocardiography (TEE) in pediatric patients with extracorporeal life support, we performed 19 TEE in 9 children (age 10 days- 4 years, weight $2.7-12 \mathrm{~kg}$ ) in mechanically assisted circulation for postcardiotomy cardiogenic shock. TEE provided valuable information: (1) dislocation of the cannula causing hemodynamic instability was diagnosed and corrected in two children; (2) Doppler evaluation of valvular function revealed severe malfunction in two patients; (3) intracardiac thrombus could be clearly detected in two children with seriously impaired hemodynamics; these findings were followed by therapeutic interventions; (4) left ventricular function before attempted weaning from cardiac assist was moderately reduced or normal in the survivors, but poor in the non-survivors. In conclusion, TEE is a valuable contribution to improved patient management during cardiac assist.

\section{7}

Effectiveness and safety of new thin-walled endotracheal tube with a novel laryngeal seal design

Reali-Forster C, Kolobow T, Giacomini M, Hayashi T, Horiba K, Ferrans VJ P-CCM, NHLBI, NIH, Bethesda, USA

We have developed a new ultrathin-walled two-stage endotracheal tube (UTETT, wall thickness $0.2 \mathrm{~mm}$ ), in which the oropharyngeal section was $2 \mathrm{~mm}$ langer than thetracheal section. Theflowresistance of the UT-ETT was4-9times lower compared to conventional ETT. The laryngeal portion of the UT-ETT was oval-shaped to accommodate the configuration of the opening of the glotris better. A laryngeal seal was made of 12-20 toroidal shaped sheets (gills) of polyurethane film (diameter $2.5 \mathrm{~cm}$, thickness $25-75 \mu \mathrm{m}$ ). There was no inflatable tracheal cuff. The new UT-ETT was evaluated in a controlled randomized study in sheep (weight $23.2+4 \mathrm{~kg}$ ). In the control group ( $\mathrm{n}=5$ ), the sheep were intubated with a $8 \mathrm{~mm}$ Mallinckrodt ETT (with hi-lo cuff, maintained at a pressure of $25-30 \mathrm{~cm} \mathrm{H}_{2} \mathrm{O}$ ). In the study group $(\mathrm{n}=4)$, the sheep were intubated with aUT-ETT of thesamedistal external diameter. Borh groups were ventilated on continuous positive pressure ventilation (CPPV) for $24 \mathrm{hr}$, at 10-12 bpmandwithatidal volume(VT) of $10-15 \mathrm{ml} \cdot \mathrm{kg}^{-1}$. Airleakwasmeasured at start, $8 \mathrm{hr}$ and $24 \mathrm{hr}$, ar baseline peak airway pressures (PIP), and when PIP was transiently raised in increments of $5 \mathrm{~cm} \mathrm{H}_{2} \mathrm{O}$ up to $50 \mathrm{~cm} \mathrm{H}_{2} \mathrm{O}$. Fluid leak was assessed using methyleneblueinfused into theoropharynx. In thecontrol group, we found minimal air leak ( $<5 \%$ up to a PIP of $50 \mathrm{~cm} \mathrm{H}_{2} \mathrm{O}$. Grossly, tracheal abnormalities ranged from erythema to erosion of the mucosa in contact with the cuff, extending beyond 4 tracheal rings. The vocal processes of the arytenoid cartilages showed changes ranging from mucosal erythema to erosion, involving an area of 3-5 mm indiameter. In thestudy group, minimal air leak was recorded up to a PIP of $45-50 \mathrm{~cm} \mathrm{H}_{2} \mathrm{O}$. The vocal processes showed mucosal erythema limited to an area of 2-3 $\mathrm{mm}$ in diameter. In condusion, the no pressure seal design is highly efficient in avoiding air leak and preventing aspiration. With the newETT there was no damage to the rachea, as there was no inflatable tracheal cuff. The laryngeal changes produced by intubation and ventilation were less pronounced with the UT-ETT than with the standard ETT.

58

A retrospective analysis of the efficacy of the Infant Star HFV ventilator in newborn infants

van der Hoeven MABHN, Jonkers M, Degraeuwe PLJ, Maertzdorf WJ, Blanco CE

Department of Neonatology, University Hospital, Maastricht, The Netherlands

In a recrospective clinical study, 63 preterm and term newborn infants were offered rescue treatment with HFV for respiratory failure under conventional ventilation. Selection criteria were $\mathrm{PIP} \geq 25 \mathrm{~cm} \mathrm{H}$ O or $\mathrm{pH} \leq 7.25$ and $\mathrm{paCO}$, $\geq 60$ torr. HFV was delivered bytheInfantStar(InfrasonicsInc.,San Diego, CA), a ventilator providing conventional ventilation $(\mathrm{CV})$ and $\mathrm{HFV}$ or both simultaneously (HFV/CV). HFV/CV settings were $32.7 \pm 9.2 \mathrm{~cm} \mathrm{H}_{2} \mathrm{O}$ (PIP) with a frequency of $0-20 / \mathrm{min}$, while the HFV pressure amplitude (DP $31 \pm 8.6$ $\mathrm{cm} \mathrm{H}_{2} \mathrm{O}$ ) varied around the adjusted positive end-expiratory pressure (PEEP)

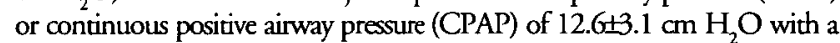
frequency of $10-15 \mathrm{~Hz}$. The following dara were obtained or calculated: conventional ventilator setings and blood gases 5 and 1 hour before HFV was started. HFV ventilatorsettingsandbloodgaseswerenoted 1,6, 12 , and 24 hours after the start of HFV. The unpaired student'st test or the Fisher's exact test were used when appropriate. Forty-six patients responded to HFV, while $17 \mathrm{had}$ to go back to conventional ventilation after a mean duration of 4.3 hours. Respondersandnon-respondersdifferedsignificantly $(\mathrm{p}<0.05)$ ingestational age (respectively $29.3 \pm 3.5 \mathrm{vs} 32.9 \pm 4.4 \mathrm{wk}$ ), inbirth weight $(1316 \pm 708 \mathrm{vs} 1890 \pm 1023$ g), and in the incidence of IRDS (38/46 vs 9/17). No significant difference between responders and non-responders was recorded in lung hypoplasia, meconium aspiration and $\mathrm{CDH}$, or in pre-HFV ventilation settings. In the $\mathrm{HFV} / \mathrm{CV}$ settings, responders and non-responders differed significanty in the use of the HFV-only modewithour IMV breathes: $15 / 46 \mathrm{vs}$. 1/17. Condusions: 1) $73 \%$ of the patients responded to this HFV device resulting in both improvement in the $\mathrm{paCO}_{2}$ with a reduction of the Paw and a reduction of the $\mathrm{FiO}_{2}$; 2) this HFV device seems to be most useful in low birth weight infants suffering with IRDS; 3) the HFV only mode withour IMV breaths seems to be more effective than the combined HFV/CV mode. 
59

\section{HFOV/IMV as non-conventional ventilatory technique for} neonates

Rondio ZK, Kramarz R, Grabowski J

Department of Anesthesia and Intensive Care, National Research Institute of Mother and Child, Warsaw, Poland

Combined high-frequency oscillatory ventilation (HFOV) with intermittent mandatory ventilation (IMV) has been adapted as a nonconventional technique for weaning in newborn babies with respiratory distress. After approval by institution's ethical committee, 10 critically ill neonates with IRDS or pneumonia treated in the NICU of our Institute, were randomized to one of two groups. One group was ventilated with IMV-HFOV technique using our piston oscillator for 3 hours. Before starting ventilation, $\mathrm{FiO}_{2}$ was $<0.35$ and pulmonary compliance was slightly increased with decrease PIP. MV and VT and additional ventilatory parameters were measured by respiratory monitor Ventrak with computer registration of respiratory pattern. Improvement of respiratory mechanics was observed. The lung was inflated to higher mean volumes without having to use high peak airway pressures to maintain ventilation (oxygenation and carbon dioxide removal). This was followed by evident stabilization of ventilatory parameters; MV and VT were higher than before using this type of ventilation.
60

\section{Independent lung ventilation in pediatric patients}

\section{Marraro $G$}

Department of Anesthesia and Intensive Care, Ospedale Fatebenefratelli e Oftalmico, Milan, Italy

The availability on the market of ventilators suitable for electronic synchronization and of the bilumen tube has allowed independent lung ventilation (ILV) in newborns and children. ILV facilitates the treatment of monolateral lung pathologies and allows selective bronchial intubation during cardio-thoracic surgery. In intensive care it allows a better and more efficient ventilation of both lungs compared with conventional mechanical ventilation, reducing the overexpansion of less damaged lung and ventilating effectively the more damaged one. ILV allows the application of selective PEEP to each lung in order to achieve maximum therapeutic effect. It also favors the isolation of infected secretions, reducing the possibility of one lung infecting the other. ILV has resolved not only unilateral but also bilateral lung pathologies which are not always truly bilateral. Separate ventilation and selective PEEP to the two lungs has allowed recognition of the real pathology and, consequently, its correct treatment. In open chest surgery, it allows the complete exclusion of one lung and at the end of the operation the effective re-ventilation of the collapsed lung. In the postoperative phase of thoracic surgery, it keeps the collapsed lung re-expanded and resolves any residual atelectasis which may have formed. The methodology when used by experienced medical and nursing staff gives excellent results. Even after prolonged treatment, hemodynamic changes, pulmonary trauma and broncho-tracheal lesions have not been noted in any children treated so far.
61

Curosurf in four patients with acute respiratory distress syndrome Faccio L, Bonadeo F, Bastante G, Piazza L Ospedale Maria Vittoria, Torino, Italy

In four adult patients with early acute respiratory distress syndrome (ARDS), a single dose of $30 \mathrm{ml} / \mathrm{kg}$ of porcine surfactant (Curosurf) was given by intrabronchial instillation. The standards of admission to the study were: $\mathrm{paO}_{2} / \mathrm{FiO}_{2}$ ratios $<80$, $\mathrm{x}$-ray with typical ARDS image and compliance $<15$. Peripheral $\mathrm{SaO}_{2}, \mathrm{EGA}$ and compliance were measured before Curosurf administration and $30 \mathrm{~min}, 3 \mathrm{~h}, 6 \mathrm{~h}, 24 \mathrm{~h}, 36 \mathrm{~h}$ later.

$\begin{array}{clcccc}\text { Patient } & \text { Parameter } & \text { Before } & 30 \mathrm{~min} & 3 \text { hours } & 6 \text { hours } \\ 1 & \mathrm{SaO}_{2} & 80 & 94 & 88 & 90 \\ & \mathrm{PaO}_{2} / \mathrm{F}_{1} \mathrm{O}_{2} & 50 & 875 & 75 & 75 \\ 2 & \mathrm{SaO}_{2} & 82 & 81 & 91 & 957 \\ & \mathrm{PaO}_{2} / \mathrm{F}_{1} \mathrm{O}_{2} & 788 & 101 & 1545 & 172.5 \\ 3 & \mathrm{SaO}_{2} & 89 & 95 & 94 & 93 \\ & \mathrm{PaO}_{2} / \mathrm{FiO}_{2} & 687 & 1236 & 140 & 139 \\ 4 & \mathrm{SaO}_{2} & 866 & 88 & 945 & 95 \\ & \mathrm{PaO}_{2} / \mathrm{FlO}_{2} & 596 & 70 & 1205 & 200\end{array}$

Immediately after Curosurf administration, patients had a sudden worsening in $\mathrm{O}_{2}$ saturation, but in the I, II, III sample, all examined parameters improved significantly; 24 hours later, all examined parameters reached a steady-state within physiological range in 3 patients; they were extubated in $72 \mathrm{~h}$ and $90 \mathrm{~h}$. The fourth patient who was HIV+ and ARDS was terminal feature, worsened quickly in the $8 \mathrm{~h}$ and died 10 days later with a return to the basal conditions.

\section{2}

Prostacyclin in acute respiratory failure of newborns and children Gentili M, Pagni R, Gentili S

Pediatric and Neonatal Intensive Care Unit, ECMO Center, Salesi Children's Hospital, Ancona, Italy

Since $1994 \mathrm{PGI}_{2}$ has been used in our unit in 29 patients. Fourteen newborns were affected by PPHN due to MAS, JMD, CDH and pneumonia. Fifteen children were affected by acute respiratory failure due to interstitial pneumonia. Our entry criteria included $\mathrm{FiO}_{2}>0.7$, $\mathrm{PEEP}>7 \mathrm{~cm} \mathrm{H} \mathrm{O}_{2} \mathrm{O}$ PIP $>30 \mathrm{~cm} \mathrm{H} \mathrm{H}_{2}, \mathrm{MAP}>15, \mathrm{OI}>0.2$, Aa $\mathrm{DO}_{>}>350$. $\mathrm{PGI}_{2}$ was started with an initial dose of $5 \mathrm{ng} / \mathrm{kg} / \mathrm{min}$ and increased at 30 min intervals up to a maximum of $125 \mathrm{ng} / \mathrm{kg} / \mathrm{min}$. The mean total duration was 7 days. To verify the efficacy of the treatment, the AA examined the trend of $\mathrm{paO}_{2}, \mathrm{SaO}_{2}, \mathrm{Aa}_{2}, \mathrm{O}_{2}$ index according to ventilatory support. In some cases, it was possible to measure PAP by indwelling catheter. To verify the safery of the treatment, the AA pointed out the trend of hemodynamic parameters (invasive $\mathrm{BP}, \mathrm{Hr}$ ) according to inotropic agents (dopamine, dobutamine) and plasma expanders need. Moreover, they examined coagulation data modification (platelet count, ACT). In children it was possible to notice minor side effects such as headache and face flushing. The overall mortality was $40 \%$ in newborn and $10 \%$ in children. 
63

Inhaled nitric oxide in pediatric patients with adult respiratory distress syndrome

Müller W, Kachel W, Varnholt V, Lasch P, Geßler P

Universitäts Kinderklinik, Mannhetm, Germany

Diffuse alveolar injury and ARDS can result from various diseases at any age during infancy and childhood. ARDS is associated with pulmonary hypertension due to vasoconstriction and occlusion of the pulmonary microvasculature. Intrapulmonary shunting of venous blood and ventilation-perfusion mismatch cause profound hypoxemia and failure of respiratory therapy. In adult ARDS patients, NO as a cellular messenger of vasodilation has been used successfully to reduce pulmonary hypertension, thereby substantially improving arterial oxygenation. We studied inhaled NO in 9 pediatric ARDS pts during conventional IPP ventilation. Underlying diagnoses were sepsis (3), RS virus pneumonia (2), bacterial pneumonia (3), and severe burn injury (1). Initial $\mathrm{paO}_{2}$ ranged from $41.5-77 \mathrm{~mm} \mathrm{Hg}$ (mean 56.1), OI 19-38.7 (mean 27.4). NO was added to the respirator gas in a dose finding protocol, 3-100 ppm. In seven pts, $\mathrm{paO}$, increased significantly by $28.7-228 \mathrm{~mm} \mathrm{Hg}$ (mean 79) during NO inhalation at individually different best effect levels of NO (10-33 ppm, mean 22.6). In 2 pts the improvement was only transient $(6-18 \mathrm{hr})$, whereas it was continuous during prolonged $\mathrm{NO}$ inhalation $(99-441 \mathrm{hr})$ in the other $5 . \mathrm{PaO}_{2}$ remained unchanged in two NO nonresponders. Finally, four pts received ECMO, 2 died. NO inhalation was not complicated by any clinical deterioration. Met$\mathrm{Hb}$ increased during prolonged treatment $(0.8-2.1 \%$, mean 1.3$)$. Examinations on the respiratory burst point to a functional impairment of the neutrophil leukocytes, but the clinical importance of this finding remains to be studied. Based on these first experiences, we conclude that inhaled NO can improve oxygenarion and thus avoid ECMO for a considerable part of pediatric ARDS pts.

64

Acute effects on oxygenation with inhaled nitric oxide in the critically ill newborn and child

Biban P, Pettenazzo A, Da Dalt L, Corner P, Marzini S, Chiandetti L, Zacchello $F$

Department of Pediatrics, Pedaatric Intensive Care Unit, University of Padova, Padova, Italy

Eleven newborns with a mean GA of 33 wk (range 25-40), a mean BW of 1800 $\mathrm{g}$ (range 550-3500), and 11 children with mean age of $5.3 \mathrm{yr}$ (range $2 \mathrm{mo-18} \mathrm{yr}$ ) were treated with inhaled NO for hypoxic respiratory failure not responding to convencional trearment. On-line NO monitoring was performed either with electrochemical cells or chemiluminescence. The response to $\mathrm{NO}$ was based on changes of $\mathrm{paO}_{2}, \mathrm{OI}, \mathrm{AaDO}_{2}$, and $\mathrm{paCO}$, within the firstsix hours of treatment. Neonatal Group: Inhalation of NO (5-30 ppm) resulted in a significant improvement of oxygenation in all pts, $\mathrm{paO}$, from $39.1 \pm 4.3$ to $68 \pm 6.4 \mathrm{~mm} \mathrm{Hg}$ ( $<<0.01$ ); OI fell from $52 \pm 7.5$ to $23.7 \pm 3.9$ ( $\mathrm{p}<0.01$ ); $\mathrm{AaDO}$, fell from $618 \pm 5.6$ to $526 \pm 34.4 \mathrm{~mm} \mathrm{Hg}(\mathrm{p}<0.01)$; and $\mathrm{paCO}$, fell from $53.9 \pm 4.6$ to $39.5 \pm 2.9 \mathrm{~mm}$ $\mathrm{Hg}(\mathrm{p}<0.02)$. The majority of the parients showed an acute response within $30-$ $60 \mathrm{~min}$. Venulatory parameters could be reduced in most pes. Fight neonates survived, 3 died duringNO trearmentand therewere 2 laredeaths. Onesurvivor was treated with $\mathrm{ECMO}$. The mean $\mathrm{GA}$ and $\mathrm{BW}$ of the nonsurvivors and the survivorswere $28.8 \mathrm{wk}, 905$ gand $36.5 \mathrm{wk}, 2556$ grespectively. Pediatric Group: Inhaled $\mathrm{NO}$ showed an acute positive effect on gas exchange, mean $\mathrm{paO}_{2}$ from $54.9 \pm 4.2$ to $92.5 \pm 11 \mathrm{~mm} \mathrm{Hg}(\mathrm{p}<0.01)$, OI from $28 \pm 2.5$ to $16.7 \pm 2.2$ ( $\mathrm{p}<0.001)$,

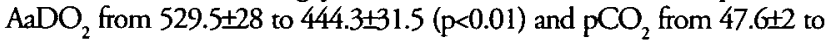
$40.8 \pm 1.6(\mathrm{p}<0.02)$. Twelve treatments with $N O$ were performedon 11 pts. Five of the 11 pessurvived. Nosideeffectswerenoted. Incondusion, the presentstudy shows that inhaled NO can exert an acute ameliorative effect on oxygenation in newbornsandchildren withsevererespiratoryfailure. Thismayallowareduction of both ventilatory parameters and $\mathrm{FiO}_{2}$, thus limiting further damage to the lungs. Nonetheless, the undertying disease seems to maintain a crucial role in the final prognosis. Further studies are needed to darify if inhalation of nitric oxide represents a new therapeutic tool. able to improve dinical outcomes.
65

Inhalation of nitric oxide using the system Pulmonox ${ }^{\circledR}$ in critically ill newborns

Stranák Z, Zábrodsky V, SimákJ

Institute for the Care of Mother and Child, Prague, Czech Republic

In a pilot study we have used inhalation of nitric oxide (NO) by the system Pulmonox ${ }^{\circledast}$ (Messer Griesheim, Austria) in ten newborns with severe pulmonary insufficiency. Maximum initial dose was $20 \mathrm{ppm}$ and a basic principle of our therapeutic protocol was to decrease the initial concentration after 6 hours as soon as possible up to $2.5-6 \mathrm{ppm}$ value. The concentration of $\mathrm{NO}_{2}$ in the inspired gas mixture was never higher than $0.5 \mathrm{ppm}$. Periods of NO-inhalation were 6-267 hours. Four patients died (bronchopulmonary dysplasia and bronchopneumonia (2), adnate sepsis (1), congenital diaphragmatic hernia (CDH) (1). Six patients survived (RDS (3), GBS sepsis (1), CDH (2)). Acure hemodynamic effect with a decrease of alveolo-arterial difference $\left(\mathrm{AaDO}_{2}\right)$ and oxygenation index (OI) was observed in patients with $\mathrm{CDH}$ only. $\mathrm{A}$ decrease of $\mathrm{AaDO}_{2}$ and $\mathrm{Ol}$ after 24 hours of NO-therapy was recorded in all surviving patients. Inhaled low dose nitric oxide using the system Pulmonox ${ }^{\circledR}$ appears to be a safe and in some cases efficacious therapy in critically ill newborns with pulmonary insufficiency.

66

Inhaled nitric oxide priming partially prevents pulmonary vasoconstriction in anesthetized newborn piglets

Hoorntje TM, Geakans G, Blanco CE

Departments of Pediatric Cardiology, Cardiothoracic Surgery and Neonatology, University Hospital Maastricht, Maastricht, The Netherlands

Hypoxia induces pulmonary hypertension by inhibiting the enzyme nitric oxide synthetase (NOS) and as a consequence decreasing NO production. We asked if this can be prevented by providing inhaled NO $(80 \mathrm{ppm})$ before and during a hypoxia challenge. Eight newborn piglets (11-18 days, $3.2-5.2 \mathrm{~kg}$ ) were instrumented under general anesthesia and curare. Catheters were placed in the femoral artery and vein for blood pressure and sampling. Through a left thoracotomy, transonic flow probes were placed around the pulmonary trunk and ascending aorta. A fiberoptic catheter was inserted in the pulmonary artery, distal from the flow probe for continuous measurement of mixed venous saturation and PA pressure. Another catheter was placed in the left atrium for pressure measurement. The piglets were mechanically ventilated with a mixture of $\mathrm{N}_{2} / \mathrm{O}_{2}$. We started with a $\mathrm{FiO}_{2}$ of 1.0 and gradually decreased it to 0.1 . After a recovery period, priming with $\mathrm{NO}$ at $80 \mathrm{ppm}$ was started and the same protocol followed. Values for pulmonary resistance were plotted against the different values of mixed venous $\mathrm{pO}_{2}$, with or without $\mathrm{NO}$ inhalation. In conclusion, hypoxia produces pulmonary vasoconstriction by decreasing NO production at the level of NOS. Priming with NO partially prevents hypoxic vasoconstriction. 
67

Can nitric oxide prevent platelet activation and platelet membrane protein changes during extracorporeal life support?

Mellgren K, Friberg $L G$, Wadenvik $H$, Mellgren $G$

Department of Pediatric Surgery, East Hospital and Department of Medicine, Sahlgrens Hospital, University of Göteborg, Göteborg, Sweden

Hemorrhage, especially intracranial bleeding, is a major complication in ECLS, experienced in 10-35\% of treated cases. An ECLS-induced platelet dysfunction might significantly contribute to this complication. Two identical in vitro ECLS systems were primed with fresh, heparinized human blood and circulared for 24 hours. NO (15 and $40 \mathrm{ppm}$, respectively) was added to one of the oxygenators. Release of betathromboglobulin, serotonin and glycocalicin were assayed and platelet membrane glycoproteins were measured using flow cytometry. In conclusion, nitric oxide seems to have a protective effect on platelet number and on platelet membrane glycoproteins (GP) during ECLS. Further studies are warranted.
68

Chronic lung disease with acute viral bronchiolitis-can nitric oxide inhalation be helpful?

Menghini P, Somaschini M, Giozani M, Lorini L, Colombo A Neonatal Intensive Care Unit, Department of Anesthesiology, Ospedali Riuniti, Bergamo, Italy

Inhalation of nitric oxide (NO) has been shown to cause selective pulmonary vasodilatarion and increase arterial oxygenation in patients with severe respiratory failure. We administrated inhaled NO to a 4-month-old infant with bronchopulmonary dysplasia and acute viral bronchiolitis. The aim of this treatment was to reverse the severe hypoxemia or to eventually decrease $\mathrm{FiO}_{2}$ and ventilatory support, reducing the ventilator-associated lung injury. A premature infant with RDS and interstitial emphysema was mechanically ventilated for 3 months and developed chroniclung disease. One month after extubation, a sudden worsening of the respiratory function due to acute viral bronchiolitis again required intubation and mechanical ventilation. Marked pulmonary hypertension was detected by echocardiography. The infant was hypoxemic with $\mathrm{FiO}, 0.9$ and attempts to reduce ventilatory support were unsuccessful. Considering the risk of possible toxicity and the variability of $\mathrm{NO}$ response, $\mathrm{NO}$ inhalation was started at a low dose, $8 \mathrm{ppm}$, and increased to a maximum of $15 \mathrm{ppm}$. The $\mathrm{pO} / \mathrm{FiO}_{2}$ ratio improved raising from 38 to 120. NO inhalation allowed reduction of the ventilatory support and $\mathrm{FiO}_{2}$ was decreased from 0.9 to 0.5 after 22 hours. The infant was weaned at $7 \mathrm{ppm}$ and $\mathrm{NO}$ was definitively discontinued after 31 hours. $\mathrm{NO}_{2}$ levels remained undetectable, maximum methemoglobin level reached $3.4 \%$ and systemic pressure was not affected during the treatment. The infant was extubated after surgical excision of laryngeal granuloma and discharged 1 month later. In conclusion, low dose $N O$ inhalation appeared effective in reversing the severe hypoxemia with pulmonary hypertension due to acute bronchiolitis. The subsequent reduction of inspired oxygen concentration and ventilatory support might have been useful in limiting the iatrogenic lung injury in this infant with an underlying chronic lung disease.
69

Extracorporeal life support-complications with heparin-coated circuits in children

Biarent D, Bouton J-M, Vanderrieviere J, De Munter C, Desay $H$ Hopital Universitaire des Enfants Reine Fabiola, Université Libre de Bruxelles, Brussels, Belgium

Since 1992,4 newborns (GA38 $\pm 1.5 \mathrm{wk}$, mean age $108 \pm 37 \mathrm{hr}$ ) and 6 children (mean age $28 \pm 18$ months) were placed on extracorporeal lung assistance (ELS) 12 times for a total duration of $2000 \mathrm{hrs}$ and mean duration of $6.9 \pm 6.9$ days. The cannularion was venovenous (5) and venoarterial (7). The circuit was set up with a biomedicus centrifugal pump and two parallel polypropylene hollow fiber oxygenators (Minimax) and coated with covalently bound heparin (Carmeda). The 3 last circuits were set-up with a nonheparinized silicone membrane (Jostra), because of plasma leaks through the Minimax oxygenators. Diagnoses were ARDS (3); diaphragmatic hernia (2); low cardiac outpur (2), pulmonary hypertension (2); septicshock with cardiac arrest (1). Five infants had hypoxia $<40$ torr and 5 needed a continuous infusion of epinephrine $>1 \mu \mathrm{g} / \mathrm{kg} / \mathrm{min}$. The most serious problem encountered was plasma break through the polypropylene membranes after 3 to 4 days on ELS. Plasma leaks recurred faster after each replacement of membranes and reached $400 \mathrm{ml} / \mathrm{hr}$ in a newborn causing hemodynamic and ionic disturbances. The plasma leak was always accompanied by mixed jaundice (bilirubinemia $>6 \mathrm{mg} / \mathrm{dl}$ ) and anuria. After the replacement of those membranes by silicone membranes, problems of jaundice, plasma leak or anuria did not occur. Other complications were hemorrhagic episodes (4), cardiac stun (13), multipleorgan failure (4). Seven children could be weaned from the bypass. Two of them relapsed with lung disease and died despite a second bypass. One infant died later from cardiac pathology. Three infants and a newborn did well and were discharged $27.5 \pm 9.2$ days after beginning ELS. These results represent a learning curve; ELS was used in the beginning as a rescue technique. Thecomplicationslinked to the polypropylene membranes could be related to the poor condition of the children before ELS. Nevertheless, jaundice and anuria occurred only with these membranes.

70

Extracorporeal lung assist in case of severe acute respiratory distress syndrome- exchange of the extracorporeal circuit does not influence the clinical course

Engel T, Höltermann W, Lennartz $H$

Department of Anaesthesiology and Intensive Crae, Philipps-University Marburg, Marburg, Germany

Extracorporeal venovenous long-term bypass is an established therapy in cases of severe acute respiratory distress syndrome (ARDS). Besides the acute respiratory failure, the inner surface of the extracorporeal circuit is also a strong activator of the complement system. Approximately every sixth day, an exchange of the membrane oxygenators and tubes is necessary because of plasma leakage or loss of function. In ten patients undergoing extracorporeal lung assist (ECLA) due to severe ARDS, we studied the clinical changes following the first exchange of the extracorporeal circuit. Hemodynamic changes, which were established within one hour after the exchange of the extracorporeal circuit, reached their maximum six hours later. Mean arterial, pulmonary and central venous pressures dropped, as did PCWP and cardiac index. Systemic and pulmonary vascular resistance increased and there was a higher consumption of norepinephrine. Twenty-four hours later, all hemodynamic parameters had returned to the initial values. The changes in pulmonary gas exchange reached their maximum fifteen minutes after the exchange of the extracorporeal circuit. The arterial oxygen $\left(\mathrm{paO}_{2}\right)$ decreased to its lowest level and simultaneously the $\mathrm{AaDO}_{2}$ increased. In the next 24 hours $\mathrm{paO}_{2}$ and $\mathrm{AaDO} 2$ improved to values better than before. The extravascular lung water (EVLW), measured by a double indicator method, increased slightly, with its maximum in the sixth hour. Twenty-four hours later the EVLW had returned to the previous value. The exchange of the extracorporeal circuit in patients undergoing ECLA due to severe ARDS was followed by a short-term deterioration of the hemodynamic and pulmonary parameters but had no influence on patient outcome. 
71

Performance of a heperanized hollow fiber oxygenator-a long-term experimental study comparing two different fibers

Crotti S, Chiumello D, Tubiolo D, Ravagnan I, Pelosi P, Gattinoni L Istituto di Anestesia e Rianimazione, Ospedale Magiore Policlinico, IRCCS, Milano, Italia

We compared the performance of a heperanized hollow fiber oxygenator (Medtronic, Minimax) featuring either the current Celanese fibers (Group A) or the Enka fibers, smaller pore size and inner diameter with thicker wall (Group B). Eight sheep (4 each group) were maintained on venovenous extracorporeal bypass for 72 hours. A centrifugal pump drove the blood through the circuit including oxygenator and heat exchanger. Comparisons were obtained at 6 hour intervals and at 3 different blood flow rates (BF) 400,800 and $1200 \mathrm{ml} / \mathrm{min}$. The oxygenator was ventilated at constant gas flow rate, $41 / \mathrm{min} \mathrm{O}_{2}$, and inlet $\mathrm{paCO}_{2}$ was maintained within $45-50 \mathrm{~mm} \mathrm{Hg}$. The $\mathrm{CO}_{2}$ transfer rate $\left(\mathrm{VCO}_{2}\right)$ was computed measuring the $\mathrm{CO}_{2}$ fraction of the exhausted gas with an infrared analyzer. Blood $\mathrm{pO} 2$ at the inlet and outlet were also measured, but no attempt was made to keep a constant inlet $\mathrm{paO}_{2}$ (mean value $51.3 \pm 10.4$, range $30-80 \mathrm{~mm} \mathrm{Hg}$ ). Pressure drop (DP) across the oxygenator was measured at each step. The results (average of all time intervals) are reported in the Table.

$\begin{array}{ccccc} & \begin{array}{c}\mathrm{BF} \\ (\mathrm{m} 1 / \mathrm{mn})\end{array} & \begin{array}{c}\mathrm{VCO}_{2} \\ (\mathrm{~m} l / \mathrm{min})\end{array} & \begin{array}{c}\mathrm{pO}_{2} \text { outlet } \\ (\mathrm{mm} \mathrm{Hg})\end{array} & \begin{array}{c}\mathrm{DP} \\ (\mathrm{mm} \mathrm{Hg})\end{array} \\ \text { Group A } & 400 & 37 \pm 15 & 491 \pm 84 & 16 \pm 6 \\ & 800 & 56 \pm 15 & 382 \pm 78 & 38 \pm 11 \\ \text { Group B } & 1200 & 66 \pm 17 & 317 \pm 95 & 64 \pm 16 \\ & 400 & 46 \pm 17 & 481 \pm 66 & 19 \pm 14 \\ & 800 & 62 \pm 16 & 349 \pm 75 & 33 \pm 14 \\ & 1200 & 75 \pm 17 & 293 \pm 76 & 51 \pm 16\end{array}$

In both groups, $\mathrm{VCO}$, increased $(\mathrm{p}<0.01)$ increasing $\mathrm{BF}$ which was higher $(p<0.01)$ in Group B. Oxygenation performance was satisfactory even at the higher $\mathrm{BF}$. The increase of DP increasing $\mathrm{BF}$ was lower in Group B $(\mathbf{p}<0.01)$. 